\title{
THE VIBE OF THE EXILES: \\ Aliens, Afropsychedelia and Psyculture
}

\author{
$\bullet$ Feature Article $\longrightarrow$ \\ Graham St John \\ Griffith University (Australia)
}

\begin{abstract}
This article offers detailed comment on the vibe of the exiles, a socio-sonic aesthetic infused with the sensibility of the exile, of compatriotism in expatriation, a characteristic of psychedelic electronica from Goatrance to psytrance and beyond (i.e. psyculture). The commentary focuses on an emancipatory artifice which sees participants in the psyculture continuum adopt the figure of the alien in transpersonal and utopian projects. Decaled with the cosmic liminality of space exploration, alien encounter and abduction repurposed from science fiction, psychedelic event-culture cultivates posthumanist pretentions resembling Afrofuturist sensibilities that are identified with, appropriated and reassembled by participants. Offering a range of examples, among them Israeli psychedelic artists bent on entering another world, the article explores the interface of psyculture and Afrofuturism. Sharing a theme central to cosmic jazz, funk, rock, dub, electro, hip-hop and techno, from the earliest productions, Israeli and otherwise, Goatrance, assumed an off-world trajectory, and a concomitant celebration of difference, a potent otherness signified by the alien encounter, where contact and abduction become driving narratives for increasingly popular social aesthetics. Exploring the different orbits from which mystics and ecstatics transmit visions of another world, the article, then, focuses on the sociosonic aesthetics of the dance floor, that orgiastic domain in which a multitude of "freedoms" are performed, mutant utopias propagated, and alien identities danced into being.
\end{abstract}

KEYWORDS: alien-ation; psyculture; Afrofuturism; posthumanism;

psytrance; exiles; aliens; vibe

GRAHAM ST JOHN is a cultural anthropologist and researcher of electronic dance music cultures and festivals. He is the author of six books including Global Tribe: Spirituality, Technology and Psytrance (Equinox 2012) and Technomad: Global Raving Countercultures (Equinox 2009), Adjunct Research Fellow at the Griffith Centre for Cultural Studies, Griffith University, Australia, and Executive Editor of Dancecult. His website is <www.edgecentral.net $>$.

Dancecult: Journal of Electronic Dance Music Culture 5(2): 56-87

ISSN 1947-5403 @2013 Dancecult http://dj.dancecult.net

DOI 10.12801/1947-5403.2013.05.02.04

dsncecult 
Power Source's (1996) hypnotic "Goaway" features the line: "music is different here, the vibrations are different, not like planet Earth". And later, amid the driving rhythm, "we will effect the vibrations". Sampling Sun Ra from the 1974 Afropsychedelic feature film Space is the Place, this mid-1990s Israeli Goatrance production evokes the desire among practitioners and enthusiasts of the psychedelic aesthetic to build a marginal and expatriate lifestyle in exile from the maligned parent culture; to fashion a difference that is pressed into the social aesthetic, the vibe, of the psychedelic trance dance party. From all-night party to week-long festival, appealing to those hailing from many nations and speaking a multitude of languages, the vibe of the exiles reverberates in the present with the proliferation of global psyculture. With its diverse musicological roots, the psychedelic electronic dance music counterculture emerging in Goa, India, in the late 1980s known as "Goatrance" was the wellspring for the flourishing of psychedelic trance (or "psytrance") around the world from the mid-1990s (see St John 2012a). Psytrance shares music production technologies and DJ techniques with other electronic dance music cultures (EDMCs), including "Detroit techno". With its distinct psychedelic sonic and visual aesthetics, organisations and parties, psytrance is distinguishable from that which is popularly marketed as "Trance" (e.g. progressive trance, eurotrance, hard trance). While producers and participants are predominantly, but by no means exclusively, white, psytrance shares a largely unrecognised psychedelic aesthetic heritage with Afrodiasporic musics.

Decaled with space exploration motifs, resounding with ascensionist discourse and alien encounters lifted and repurposed from science fiction cinema, psychedelic eventculture is richly inscribed with an off-planetary utopianism holding much in common with Afrofuturist becomings. The article explores the interfacing of psyculture and Afrofuturism, dissecting freak counterculturalist and Afrodiasporic imaginations, offering commentary on the appropriation and remixing of the aesthetics of alienation. The meaning of "alienation" I use requires unpacking here. In standard psycho-sociological conceptualisations, "alienation" refers to the effects of disenfranchisement, exclusion, an absence of authenticity. It is the disenchantment cumulating from oppressive social systems, power's limits on freedom, and the denials of humanity, from slavery to bureaucracy. But the study of alienation has typically addressed the cultural artifice propagating in the face of power. And thus we observe the communities and artists in exile forming in response to oppression, as can be observed in the posthumanist interventions of black science fiction authors, hip-hop artists and Detroit techno musicians. Neither definitively utopian nor dystopian, here, the "Alien Nation" is decidedly heterotopian, if Mark Sinker's (1992) original whirlwind of digressions is any chart to navigate. In Sinker's postulations, the chief characteristic of these artforms is, nevertheless, "survival; by syncretism, by bricolage, by a day-to-day programme of appropriation and adaptation as resourcefully broad-minded as any in history".

Such strategies are integral to the remixological praxis of EDM cultures, not the least of all psychedelic electronica. In the language I adopt, where usage connotes the alien 
of extraterrestrial or interdimensional infamy, to be alienated is to access a potentially emancipatory liminality not dissimilar to that identified by Sinker. I identify two notunrelated modes. In the first, the figure of the alien is appropriated to gnostic objectives, embodying an otherness the adoption of which may be integral to self-discovery. The alien, typically but certainly not exclusively benevolent, is adopted within psycho-cultural arts as a vehicle of re-enchantment. Alienation is then a performance of self-virtualisation, where the journey (intergalactic or otherwise) is a narrative of self-metamorphosis and the alien a transpersonalising device, enabling a self-transcendence achievable with the assistance of a spectrum of sensory technologies (see St John 2013a). With the second mode that will figure prominently in this article, and which is differentiated here as alien-ation, we turn the original meaning on its head. The figure of the alien, as a symbol of ultimate difference, collapses all distinctions, becoming a utopian (or indeed dystopian) signifier, holding appeal to the excluded, to the dislocated, to the alienated. Here we find the practice of alien-ation as a possible architectonic of salvation, where sensory technologies are adopted to effect altered social conditions; a socio-sonic aesthetic, or vibe, the optimised aesthetics of abduction, propagating the conditions of freedom desired in contradistinction to those beyond the event. It is little wonder that Israelis, as we'll observe, find truck with Afrofuturisms, and will deploy and appropriate such utopian constructs, despite the very different histories of oppression.

\section{THE VIBE}

Electronic Dance music CUlture is a product of the interfacing of European and Afrodiasporic cultural aesthetics, social practices and sonic techniques. Over some four decades, a techno-liberationism has animated EDM genres, scenes and movements (and indeed other popular music forms). EDMCs are futurist technocultures whose post/ humanist forms are embellished with dramatic quests for freedom born from estrangement, and flushed with a sensibility of transit, of movement, albeit so often a "movement" without objective, a revelation without content, and which is nevertheless potent, archetypally liminal, which derives from the Latin "limen", meaning threshold. Cults of expectancy have arisen in which a contingent technics is venerated by disaffected populations in the faithful application of a mechanics of transcendence enabling rupture from the past, and an escalation into the future that is lived in an ongoing and dramatic present. With Hermetic and Afrofuturist inspiration, these dance cultures are fashioned according to repurposed design and chance arrangements, with sonic artifice, computer technology and sci-fi cinema appropriated in pursuit of the raceless ascension, cyborgian mutation, the alien nation. Although variously expressed, the ultimate compulsion here is an expatriation into universality, a merger with the divine, with electronic synthesizers the hallmark instrumentation through which the ascension is sought and obtained. But while synthesis orchestrates cosmic contact, it also facilitates contact with one's fellow travellers. Thus, while prosthetically enhanced fantasies may enable disembodiment or out-of-bodiment, this synthetic-millenarianism is not removed from the domain of ecstatic sociality and 
embodied experience-from dance. Indeed, often conceptualized as the Mothership, pulsating womblike, the dance floor remains integral, pregnant with possibility. Thus, the appropriate place to begin here is with the socio-sonic fusional aesthetic that would come to signify an optimum dance-music experience: the vibe.

According to Sally Sommer (2001-02: 73), who attempts to define the experience in underground house clubs, the vibe is "an active communal force, a feeling, a rhythm that is created by the mix of dancers, the balance of loud music, the effects of darkness and light, the energy. Everything interlocks to produce a powerful sense of liberation. The vibe is an active, exhilarating feeling of 'now-ness' that everything is coming together". And EDMCs have historically evolved technics to optimize the vibe. The Oxford English Dictionary (3rd ed.) indicates that the vibe entered popular literature in 1967, more-than-likely a result of the "happenings" and the psychedelic jouissance of the so-called Summer of Love. But the experience inherited by contemporary EDM and other popular music cultures has had a convoluted history. For one thing, the vibe appears rooted in African American dance music culture, particularly jazz. But the roots of collective altered states in African American dance music are much deeper; if we are to follow Shapiro (2005: 90), who traces the "capitulation" to "machine rhythms" back through funk and New Orleans swing to late $19^{\text {th }}$ Century brass bands composed of freed slaves and immigrants from Haiti and Cuba congregating in New Orleans' Congo Square; or if we are to follow Robin Sylvan (2002), who attempts to trace the "spirit" observed in popular music and dance forms to West African possession cults. With the advent of underground dance music in New York in the 1970s, the "vibe" would become especially "meaningful", claims Kai Fikentscher in You Better Work! (2000: 82), "for culture bearers of the African American tradition and those who have learned its idiom", the word becoming a likely carrier of the "subversive intelligence", which John Leland suggests, in his Hip: The History (2004: 6), was cultivated by transplanted (slave) outsiders and their descendants, and lies at the roots of "hip". "With this history in mind, the "vibe" is inherently a subversive dance music experience, a virtual world enabling a measure of cultural autonomy and even integration within an oppressive, alien, world.

Yet, in a parallel development, the term "vibration", of which "vibe" is a contraction, has been in currency since at least the mid-nineteenth century, according to the $O E D$, designating an "intuitive signal" that may be picked up from other people and the atmosphere. While the $O E D$ shows no connection, vibration is likely to have gained popular usage in connection with the Eastern-inspired Theosophical Society and varying "spiritualist" traditions purporting to gauge, measure, reflect, channel and translate "vibrations", to offer readings of energy, the soul, spirit, nature, universe, God. Received traditions hold varying recognition that divinity inheres in a "universal sound" or "undertone", commonly represented in the Hindu sacred syllable "Om". Recognition that the self is realized, obtains potential and maintains balance, through techniques such as meditating, channeling, divining or amplifying vibration (or God) has been integral to the holistic-health and newspirituality movement, as well as "New Age" music. But notably, the idea that vibrations 
can be distorted or re-directed, are integral to musique concrète, noise artists and pioneering musicians who have worked to "effect the vibrations", which Sun Ra associated with a utopian "transmolecularization" to "another world". In what Erik Davis (2002) calls the "electromagnetic imaginary" from the late nineteenth century, inventions like the telephone, phonograph, radio and theremin (and later synthesizers and samplers) were transmuting sound vibrations into information with "technologies of perception" enabling new modes of self-expression and social interaction.

In the long prelude to the Summer of Love, it is likely that the vibe thus entered the countercultural lexicon via the complex intersecting lines of African and European trajectories. White hipsters, beats and their antecedents who had found the alienated sensibility of jazz and bebop scenes appealing, and may have been among those Norman Mailer (1957) admonished as "white negroes", slouched into this groove. From cosmic jazz artists, among whom Sun $\mathrm{Ra}$ and his Galactic Research Arkestra were meteoric, to cosmic rock experimentalists The Grateful Dead, musicians manipulated oscillators and produced feedback to simulate and enhance altered states appealing to participants in an emergent psychedelic culture. Tim Leary and Stewart Brand (and thus Eastern mysticism and cybernetics) were most influential. With coauthors Ralph Metzner and Richard Alpert, Leary deliberated on source "wave-vibrations" at some length in The Psychedelic Experience: A Manual Based on the Tibetan Book of the Dead (1964). By 1966, Whole Earth Catalogue founder, Brand, along with Ken Kesey, the Merry Pranksters and house band The Grateful Dead, were organizing the setting for the "freak-out" at the Trips Festival on January 21-23 at San Francisco's Longshoreman's Hall. By sharp contrast to the soulless world of bureaucracy and the military they railed against, in the "Acid Tests", Brand had constructed "a world in which he and the dancers on the floor were part of a single, leveled social system". In the experimental, multi-media happening, "stereo gear, slide projectors, strobe lights, and, of course, LSD, all had the power to transform the mind-set of an individual and to link him or her through invisible 'vibes' to others" (Turner 2006: 76, 240). At this time, the vibrations had also been raised in New York, where, with direct influence from Leary, David Mancuso operated proto-disco deprogramming rituals at The Loft at 647 Broadway (see Lawrence 2003: 9-10) where Afro-American (and later legendary) DJs Larry Levan and Frankie Knuckles (among others) hung out. Levan would become a radical-remixer known for keeping the dance floor at the Paradise Garage in thrall like no other, and Knuckles is a technical innovator who worked with reel-to-reel tape and manned the decks at The Warehouse in Chicago. While the DJ-dancer interaction and the role of rhythm as a "synchronizing" force have been observed as integral to the "collective energy", or vibe, of New York underground clubs (see Fikentscher 2000), as we scan the horizons of EDMC it becomes apparent that motivation and intention modulate this "energy". That is, additional to music programming and response, and avant-garde technique, the vibe is conditioned by manifold freedoms sought and obtained within its domain (see St John 2009). The aesthetic that is explored here is that of the exile. 


\section{Disctopia: The Vibe of the EXILES}

EDMCS HAVE LONG BEEN CONSIDERED SANCTUARIES from oppression and prejudice for marginal and excluded populations. One of the earliest New York dance clubs was indeed called The Sanctuary, the converted German Baptist church where the inventor of slip-queuing and beat-matching, Francis Grasso, worked the turntables. In The Secret History of Disco, Peter Shapiro documents how a clandestine mood, a flight from fascism, influenced the style and architectonic of underground dance clubs long after the Nazis outlawed the Hamburg "Swing Kids" or sent the occupants of Parisian discothèques to labour camps (Shapiro 2005: 14-15). That is not to say that the queer disco and house scenes in New York and Chicago in the 1970s and 1980s weren't oases from oppression, for they indeed enabled young men, many of whom were both gay and African-American, ItalianAmerican or Latino, opportunities to explore their identities and their sexuality beyond the homophobic world of "straights". Fikentscher notes that in venues like the Paradise Garage and The Warehouse, "the idea of 'paradise' has been repeatedly invoked or pursued in song and dance, to contrast it with that other nonparadise, the world outside, with its persistent social inequalities and violent conflicts" (2000: 62). The kinaesthetic maelstrom of the dance floor provides a ritualized space for relatively uninhibited expression and re-inscriptions, the spectacular performance and re-mastering of the self, the performance of difference maligned, scorned and censured outside. In this club culture, excluded populations could "jack the groove" under metronomic rhythms, the machine sensibility purposed to "process rather than result (procreation)" (Shapiro 2005: 111). As Tim Lawrence (2003: 233) points out, in the "denaturalized sexual environment" of the temporary androgynous zone, "trancesexuals" came to flourish. From early-1980s house clubs through early-1990s raves mounted across continents (McKay 1996, 1998; Silcott 1999; St John 2001), dance floor habitués in exile from The Occupation, Babylon, Straights, The Law, Disenchantment, Cheese, held sovereignty over mini free-states-an Altered State.

This state of virtual secession in which liberty was experienced in the sovereign realm of the dance floor demonstrates evidence of an evolved longing, a disctopianism raised and sustained from an assemblage of scenes, drugs, musics, technologies and mythologies; a cultural timbre resonating with Afrodiasporic futurism and Romantic asenscionism. This discultural utopia would be fueled by LSD liquefying the edges of jazz, rock, soul, funk, disco, electro, techno and ambient musics holding pastoral (see Reynolds 1997), cosmic, and/or hybrid pretentions. It has received considerable input from the cosmic rock tradition pursuing electronic and percussive experimentalism, notably The Jimi Hendrix Experience, The Grateful Dead, Pink Floyd, Hawkwind, Can and Faust. The Altered State is founded in experimental electronic music scenes whose off-world Arcadias and Futuramas were dreamt up with the aid of "the fantastic sounds of the new machinery. ... The hypnotic, other worldly quality of the timbres and the rigidly insistent mechanistic throbs of the Moog and Arp synthesizers used by disco producers like Moroder, Cowley, and Bobby O [which] summed up an aesthetic that sought to upset the 'natural' order of things" (Shapiro 
2005: 111). If utopias are extended ruptures from non-ideal worlds, then those departures, those "breaks", were prized open in 1970s New York with the assistance of Bronx block party legend Kool Herc, disco remix pioneer Walter Gibbons (Lawrence 2008), turntablist Grandmaster Flash and others whose artifice was to mix between the percussive breaks (the breaks between vocals and melodies) on copies of the same records, editing the breaks on reel-to-reel tape and pressing them to acetate, pressing the longue disco durée onto the 12 -inch record, and more generally forging a culture in which the beat was matched, cut, sampled and remixed-in which now, the liminal state of transit, was getting a permanent encore. This sensibility is intimate with the unrequited longings of soul passing into electro and hip-hop, and enhanced through sound synthesizing technologies such as the vocoder virtualizing the (black) human voice (and body) to produce "hypersoul" (see Weheliye 2002). The citizens of this freak nation were commanded to "give up the funk", notably through the directives of P-Funk leader George Clinton, a process not dissimilar to the injunction to capitulate to the rhythm under House rules. And this was despite Dr Funkenstien's fears, expressed on Uncle Jam Wants You (Funkadelic 1979), that the "sexless grooves" of disco were "denuding black music of its funk and, by extension, black people of their humanity" (Shapiro 2005: 89). It would be characterized by stylistic miscegenation, fusions of disparate genres and their aesthetics, from funk, soul, synthpop, and Afrobeat, as evinced by North Italian Afro cosmic or Afro disco. ${ }^{2}$ Passengers onboard The Mothership were intimate with computers, a circumstance apparent in the early-1980s Electro-envelope pushed by Afrika Bambaataa \& Soulsonic Force, whose Planet Rock 12-inch (1982) sampled Kraftwerk's Trans-Europe Express (Nesbit 2005; Toop 1984: 130-1). The sensibility of the exile is redolent within the Detroit techno tradition adopting European synthpop, especially motorik experimental sounds fomenting with Kraftwerk, but also Tangerine Dream producer Klaus Schulze, and English New Wave acts like Depeche Mode, New Order and the EBM outfit Nitzer Ebb to produce a "deterritorialised musical sensibility to combat the fall-out of both racism and post-industrial ruin", which enabled youth cultures in Manchester, London, Berlin and elsewhere to "make sense of their experience of alienation in the rapidly emerging global technoculture" (Rietveld 2008: 17, 8). These acid house techno scenes possessed an empathetic rave-o-lutionary attitude which grew in the wake of the Ecstasy explosion at the turn of the 1990s, and was later fed by the polyrhythmic distillations of breakbeat and jungle/drum \& bass sounding out a techno-futurism (see Eshun 1998).

It should be recognized that the interior of the Mothership was therefore resonating with dubstreams indebted to the work of King Tubby, the 1960s King of Dancehall (Partridge 2007), Black Arc studio engineer Lee Perry (Katz 2000), and other midwives to the birth of remixology. And thus, the disctopia is steeped in the tradition of the "sound system", which, in Kingston from the 1960s, saw the likes of Tubby cobbling together monstrous rigs of solid bass and reverb. These "sounds", as they were known, would hold a gravitational influence on their population, with those called to gyrate and grind identifying with its corporate spirit, moving to defend it against other sounds. Talking on "sufferah music", reggae producer Derek Harriott states that "the equipment was so powerful and the vibe so strong that we 
feel it. Like when we were dancing you were actually part of [the music]. . . It was ours and so many of us wanted to do something to contribute to it" (in Slater 2006). These competitive sound-rig communities evolved over decades as local grounds of identification emigrated from Jamaica and were smuggled into hip-hop, rave and their many after parties inflected with a Rastafarian sensibility of freedom in exile. Luton's Exodus collective, for example, demonstrated a commitment to break free from Babylonian oppression (Malyon 1998), a theme invoked in the remit of a deluge of post-rave formations, including mobile "tekno sound systems" like Spiral Tribe, who, hunkering down with the travellers of Albion and their free festivals, trailblazed the international teknival movement (St John 2009).

But what will concern me more directly here is the contemporaneous quest undertaken by those who sought the way out through travels in (actual and virtual) space, those whose direct forebears might have been the "frontiersmen in the Wild West of American nightlife" (Mailer 1957: 277), or the "travelers of Albion" (McKay 1996) searching for an existential sound system. The vibe of the exile is redolent in the Goa psychedelic trance movement, whose disparate expatriates, " "displaced peoples with displaced minds" (D’Andrea 2007: 9), discover unity in exile from life-world crises under the soundtrack of neo-psychedelia. Goa, India, would be the exoteric site of propagation through the 1980s as one of the world's principal freak-destinations since the 1960s absorbed developments in global electronic dance music culture, expatriatism and psychedelic tourism through the decade. The scene there peaked in the early 1990s, after which mass tourism and criminal and regulatory forces have conspired in its demise as a genuine location for the radical immanence that has long motivated traveller enthusiasts and new-spiritual seekers (D'Andrea 2007; Saldanha 2007; Elliott 2010, St John 2012b). But as Goa declined as a scene-maker, it proliferated in a liminal-lifestyle expressed through a multitude of national scene translations (St John 2013b). The transnational Goa-diaspora was infused with an Orientation of the self, itself shaped by the quest for disorientation and self-alienation with the assistance of psychoactives, as carried in imagineer Simon Posford's (aka Hallucinogen's) journey into "Demention", the finale on The Lone Deranger (1997), and as found in multifarious projects celebrating and/or mobilizing Leary's goal of establishing the conditions for vacating the ego's "routine game reality". The departures from home, everyday life, sobriety, one's skin, one's self, the planet, enabled a resounding "yes" in response to the question posed by Hendrix, whose seminal 1967 LP, Are You Experienced, provided the inspiration for the title of the debut release of psyculture's most renowned act, formed by Posford and Raja Ram, Shpongle (Are You Shpongled?, 1998). As mentioned, "space" offers one of the critical domains of such experience, such virtuality, such enshponglement, with travel in outer-space-perhaps even "Outer Shpongolia" (from Nothing Lasts... But Nothing Is Lost, 2005) -becoming a complex narrative device for inner travail, the avatar's quest, the shaman's journey, self-realization.

As evinced by the popular mid-1990s London label and club, Return to the Source, Goa/psytrance became prominent within an electronic artifice applied as part of an assemblage of techniques adopted in the interests of consciousness expansion, and in the cultural business of re/mastering the self which pervades the rave imaginary (St John 2004). 
These are processes that are consistent with alternative spiritual paradigms that have, as Paul Heelas and Linda Woodhead (2005) identify, become flush with a contemporary culture that has undergone a "spiritual revolution". This is not far removed at all from the practices Kodwo Eshun conveys in his study of the popular "science of sensory engineering" within "Afrodelica", which, in More Brilliant than the Sun, he claims harnesses the "mythillogical principles" of sound, rhythm and vision technologies, repurposed to intensify sensations and propagate "new sensory lifeforms" (1998: A[177], A[185]). Such efforts to "technofy" thy self, evoke the flourishing technoccult reliant, like Christopher Partridge's popular "occulture" (2004), on the contemporary proliferation of cultic practice through literature, film and music, but which is here dependent on ever-newer and recombinant technics, ascensionist techno-rituals, enabling journeys towards the unknown, transcendence and metamorphosis. EDMC is replete with such alchemical techgnosis (Davis 1998), with mixing desks, turntables, synthesizers and especially the sampler-techno-alchemical devices par excellence enabling the transformation of found sound through the remix. Indeed the remix is the underlying logic here. As a voracious genre of the sonic crossroads, psyculture has absorbed a library of Afrodiasporic and other "sonic fictions", a process paralleled by the voracity, for instance, of techno, whose Detroit lineage was founded by African-Americans themselves motivated by a variety of futurist resources. EDMC is built on remixology, hacking new ware to reassemble old rites, repurposing old tech to break new sonic and kinesthetic ground. It is a sampladelic universe in which origins are notoriously difficult, sometimes impossible to trace (see St John 2012c), and where bodies are continually carving into a future that arrives in a squall of bits and a wall of bass. These genres are more accurately "meta-genres" which, in the case of psytrance, has drawn manifold aesthetics into its psychedelic orbit (Lindop 2010) among which can be included jazz, rock, ambient, funk, breaks, dub, electro, techno and industrial. ${ }^{4}$ In the process of $p$ sychedelicization, which often involves styles already liquefied by LSD, musics are modulated to the task of self-alienation.

\section{Cosmic Liminality and the InTERGalactic Trance Mission}

In Space Age popular music forms, outer space is a realm that exiles of varying backgrounds seek to inhabit. This "space" that is the "place" is external and internal, extraterrestrial and psychosomatic. A cosmic threshold. Within the psychedelic imaginary, the realms of the physical and the imagination interface such that space becomes the terrain across which one physically, or within which one psychically, travels. And the farther from routine consciousness one ranges, the more other one might become from one's self. While travel in exotic locales might potentiate self-transcendence-and such topoi have been variously simulated and achieved, from "exotic" jazz nightclubs (see Adinolfi 2008) to temperate and tropical "contact zones" (see D'Andrea 2007) - there is no farther to sojourn from one's physical-ontological routine than the space beyond the Earth's atmosphere. As it transpires, the exosphere was first subject to human exploration and conquest in the period that LSD (and other techniques of self-expansion and out-of-body experiences like meditation, yoga and flotation tanks) achieved popularity. ${ }^{5}$ From the early psychedelic period, the LSD "trip" 
gave users the impression of floating in space, a disembodied sensibility imagined with the assistance of astronauts operating in weightless conditions care of the earliest missions into orbit transmitted into homes via television (or indeed with the assistance of scenes from Stanley Kubrick's classic gnostic space opera 2001: A Space Odyssey). If, as Victor Turner had argued, marginal conditions are essentially liminal conditions, with the Space Age, humans were accessing the most physically marginal regions to date, a marginality appealing to musicians already marginalized, and who from this period onwards were building what Eshun called the "futurhythmachine".

Outer space would exert influence on psychedelic artists of many backgrounds, including those who Mark Dery (1993: 736) described as "descendents of alien abductions", those Afrodiasporic artists for whom extraterrestrial aliens would signify possibility, a controllable future, outer space becoming a "realm of pure possibility", as Turner (1967: 97) would have had it, a theme capitalized upon in science fiction and space-operatic cinema and television. If space is "the place", as in the theatre, to dramatize one's cause (one's alienation), in the Space Age, the curtain was up and the place was humming. And so, in the sonic fiction of the Afrodiaspora there emerged a script with multiple authors/actors, none more significant than perhaps the most psychedelic non-drug user in history, "mythscientist" Sun $\mathrm{Ra}$-who we might envision seated before his rocksichord and minimoog transcendence machines in gold winged-orb crowned Pharaoh's garb conducting the Universal Arkestra into an electromagnetic "polyrhythmaze". Sun Ra, we have heard, was raised on the science fiction comic book and screenplay narratives of Buck Rogers and Flash Gordon, and later studied the Science Fiction of the Nation of Islam along with Egyptology and the Bible (Szwed 1997; Zuberi 2004: 80). On a mission from Saturn, if Sun Ra's was a redemption strategy evoking theosophical beliefs about "ascended masters" intervening in and guiding humanity for millennia, he was a rogue interventionist, a sonic esoterrorist adopting "space music" to chart a course into the unknown. He announced in the 1960s that the "Space Age cannot be avoided and SPACE MUSIC is the key to understanding the meaning of the IMPOSSIBLE and every other enigma" (Eshun 1998: 09[157]). Intervening on behalf of The Intergalactic Council of Outer Space, Ra was not alone, for occupying the firmament of Black sci-fi were a motley fleet of iconoclasts, including: the Star Child himself, George Clinton, captaining the Mothership Connection and commanding the Parliamentary "funkentelechy"; Africa Bambaataa casting black vinyl UFOs towards Earth (on the cover of Planet Rock-The Album, 1986); and the vanguard of Detroit techno, whose earliest member, Juan Atkins (a.k.a. Model 500), was producing proto-techno in the year NASA launched the first black man into orbit (Guion Bluford Jr, in 1983 as a crewmember of the Space Shuttle Challenger). 


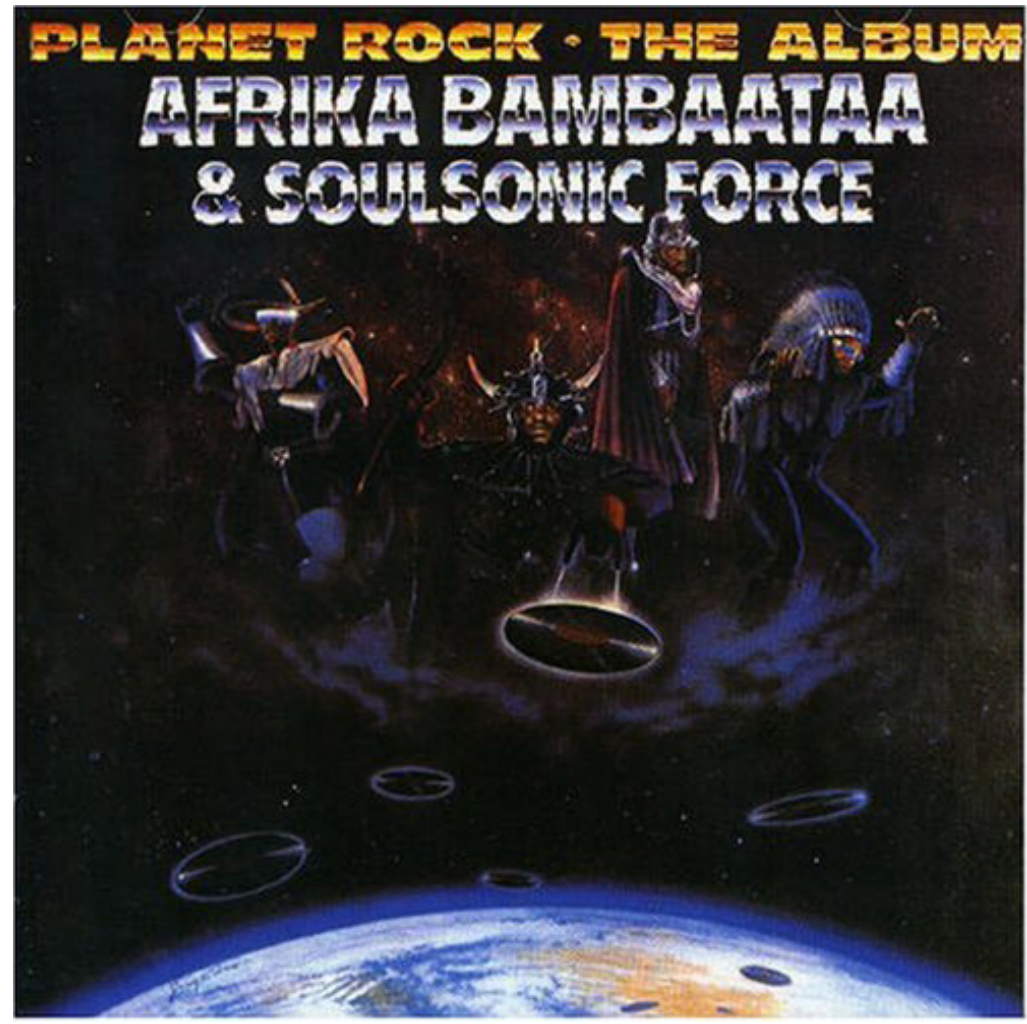

Figure 1. Cover art of Afrika BambaataA \& Soulsonic Force, Planet Rock-The Album (1986).

In the mid-1980s, as a Detroit techno legend, Atkins, was producing material like "No UFOs" (Model 500, 1985), the title suggesting identification with extraterrestrial aliens as oppressed and segregated others, a similar attitude that would be adopted towards machines in the wake of Kraftwerk. While prior to this period, the Afrofuturist Space Program was ecstatic, ad hoc and amorphous, ${ }^{6}$ with the advent of techno, it would adopt more Apollonian characteristics like restraint and control. Such would be apparent from the onset of the Detroit techno juggernaut and advanced by Underground Resistance, as evinced on 12-inch releases like The Final Frontier (1991) and through the UR outfit formed by Mike Banks, Robert Hood and Jeff Mills, X-102, whose debut Discovers The Rings Of Saturn (1992) featured tracks named after Saturn's moons. Banks also had a key role in The Martian, the outfit in which various UR members participated to produce the Red Planet 12-inch series. This was cosmic techno, with early releases like "Star Dancer" (1993) and "Lost Transmission From Earth" (off their debut Meet The Red Planet, 1992) possessing maximal electro-trance atmospherics. Mars has long been imagined the likeliest source of life in the Solar System beyond the Earth, a mystery provoking the imagination, a Red Planet pregnant with possibility. Many of the releases in The Martian series had the Zen Buddhist-like instruction "The red planet will appear only when your mind is open" printed on the vinyl. ${ }^{7}$ 


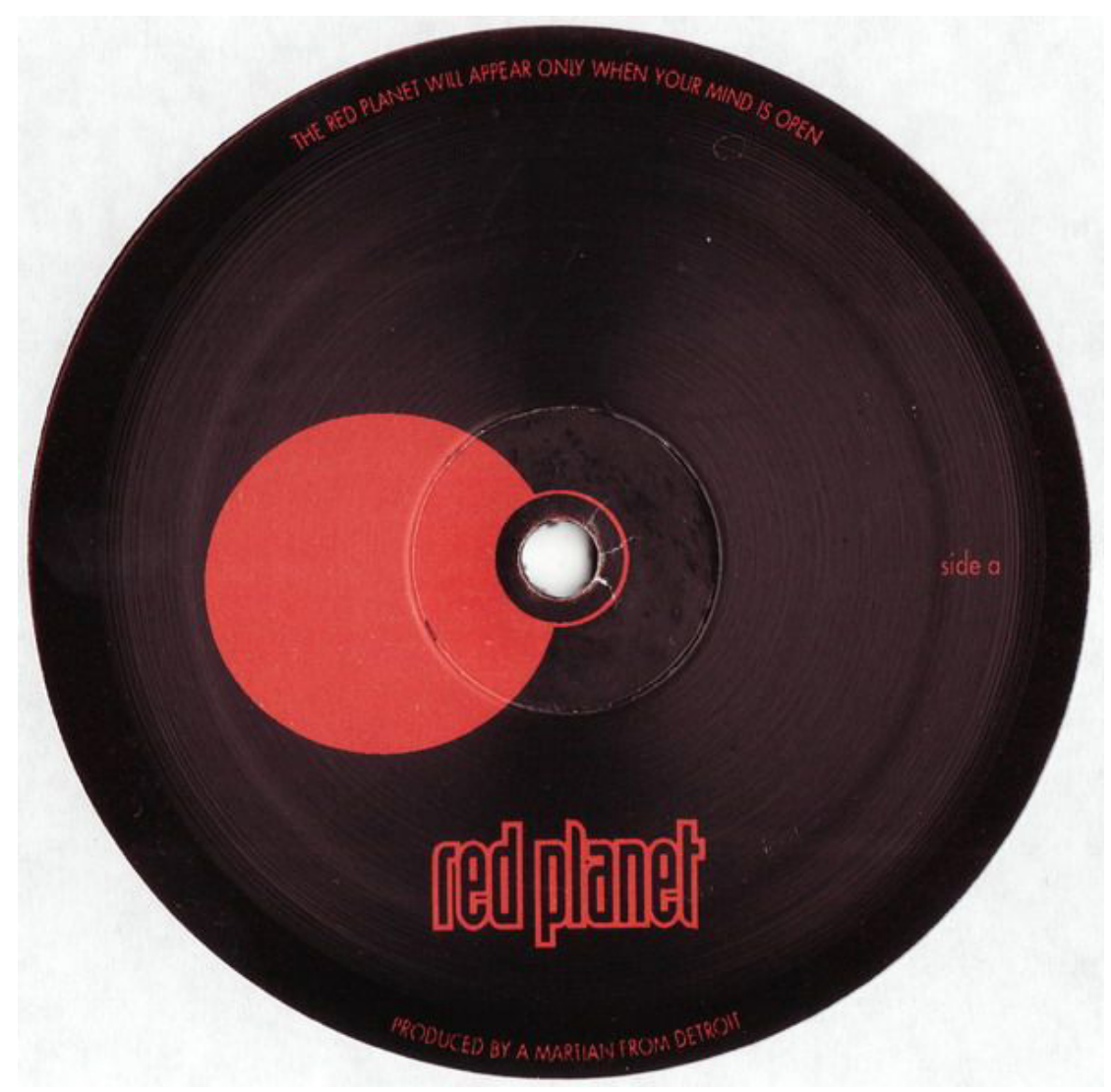

Figure 2. The Martian's Meet The Red Planet (1992).

For innovators within the Afrospace Program, pre- and post-techno, outer space is a source of mystery and hope, fusion and metamorphosis. Space was the place of becoming, new worlds forming from the dissonance generated by filters and oscillators. The odyssey would persist with New York's illbientalist DJ Spooky, and continue in, for example, the rhythmic breakbeat fusion of West London's Orin Walters (aka Afronaught). Inhabitants of the cosmic margins are readily identifiable as compatriots, as "space brothers", fellow exiles, and common themes appear across the sonic fictions of these technocculturalists, afrocosmic heads, flamboyant futurists and star sound collectives, not the least of which was the understanding that space is a cosmic canvas under whose proscenium arch the alienated could enact "cosmo-dramas" (Hollings 2002: 101) of empowerment, liberation and becoming-alien. The identification with the oppressed non-human in the form of the extraterrestrial or machine, or both, is endogenous to the Afropsychedelic trajectory, in which the alien/UFO or robot is scripted, embodied and deployed as a symbol of resistance.

Indicative of the influence that celestial bodies, especially Mars (along with the Sun and the Moon), have long exerted on artists within the psychedelic milieu, the Red Planet would pull Dino Psaras, Steve Ronan and Iain Rive into its gravity field. Their Goatrance act, Cydonia, ${ }^{8}$ was a dedication to Mars as conveyed on two major releases, Mind Hunter (1997) and the dark atmospheric In Fear of A Red Planet (1999),' with the jacket graphics 
offering co-ordinates and grids templating the dimensions of a Martian civilization. The album conveys how Goa artists were sharing off-planetary trajectories with the afronauts of astro jazz and cosmic funk, with Jamaican dreadnauts and Detroit techgnostics. Yet this was an odyssey in space also imbued with Eastern mysticism, Hindu iconography, yogic practice and the possibility of merging with the divine. This galactic Orientation was apparent, for instance, in the work of Jörg Kessler, label manager at Shiva Space Technology, or in The Overlords (Ian Ion and Rune Bendixen), whose cover design for All the Naked People (Arista, 1994) featured three sadhus and an astronaut. While overt Hindu symbolism (i.e. the Om symbol) might have lost popularity by the late-1990s as the scene receded from Goa, producers and psychonauts were remaining true to their roots. Thus the Oming sequences on Astral Projection's space-operatic "Cosmic Ascension" (Dancing Galaxy, 1997) left little doubt that the launch sequence for their full-powered mission was initiated on the subcontinent. When, on the cover of his Psykadelia (1997), Asia 2001 (Frenchman Gilbert Thévenet) projected a violet-skinned hairless and earless alien with large slanted eyes and vestigial lower face gracefully seated in lotus position with its bulbous head at the centre of a mandala, we had arrived at the juncture of two critical paths of self-discovery: the cosmic and yogic odysseys.

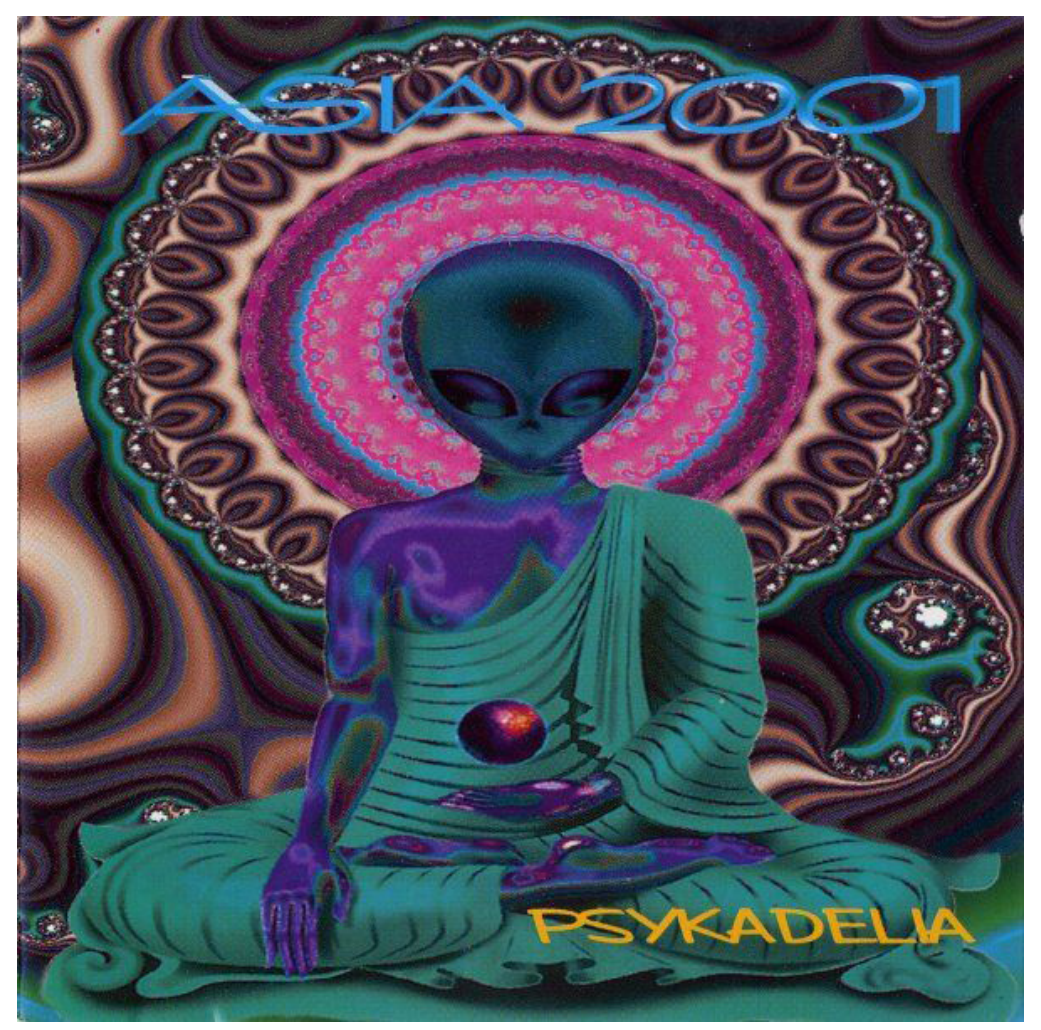

FIGURE 3. COVER ART ON ASIA 2000'S PSYKADELIA (1997). 
Together these paths evince a Romantic-ascenscionist faculty inflected with Eastern eschatology. The mood of progress is captured most evidently by the advancements in astronomy and aerospace sciences and technologies enabling human space flight, and analogizing inner flights. Such ascenscionism is implicit to a range of musics influential to the psytrance development. Free jazz pioneer, John Coltrane, whose later albums included Ascension (1965), Meditations (1965), Om (1967), Cosmic Music (1968) and the posthumous Interstellar Space (1974), echoed his interest in Indian music and channeling the universal sound "Om", a holy project not far removed from that of sadhu and dark trance legend Goa Gil (St John 2011) or probably the most instrumental Goa producer and conceptechnician, Raja Ram, himself a jazz flautist who played with 1970s psychedelic rock act Quintessence (formed in 1969). Coltrane may have been "the first Hippie" (Eshun 1998: A[183]), but Gil and especially Raja Ram would haul that aesthetic over the sonic hump. Raja Ram has probably flown more missions into infinity and back than anyone, having formed The Infinity Project in 1989 (with Graham Wood), Shpongle in the mid1990s (with Simon Posford) and later forming the influential label TIP Records (later TIP.World) which, by 2000, was still launching Spaceships of the Imagination (a two part compilation series). Pioneering ambient act, The Orb, who fused the ambience of Brian Eno (whose first release was Apollo-Atmospheres \& Soundtracks, 1983) with dub reggae, are integral to the psybient trajectory.

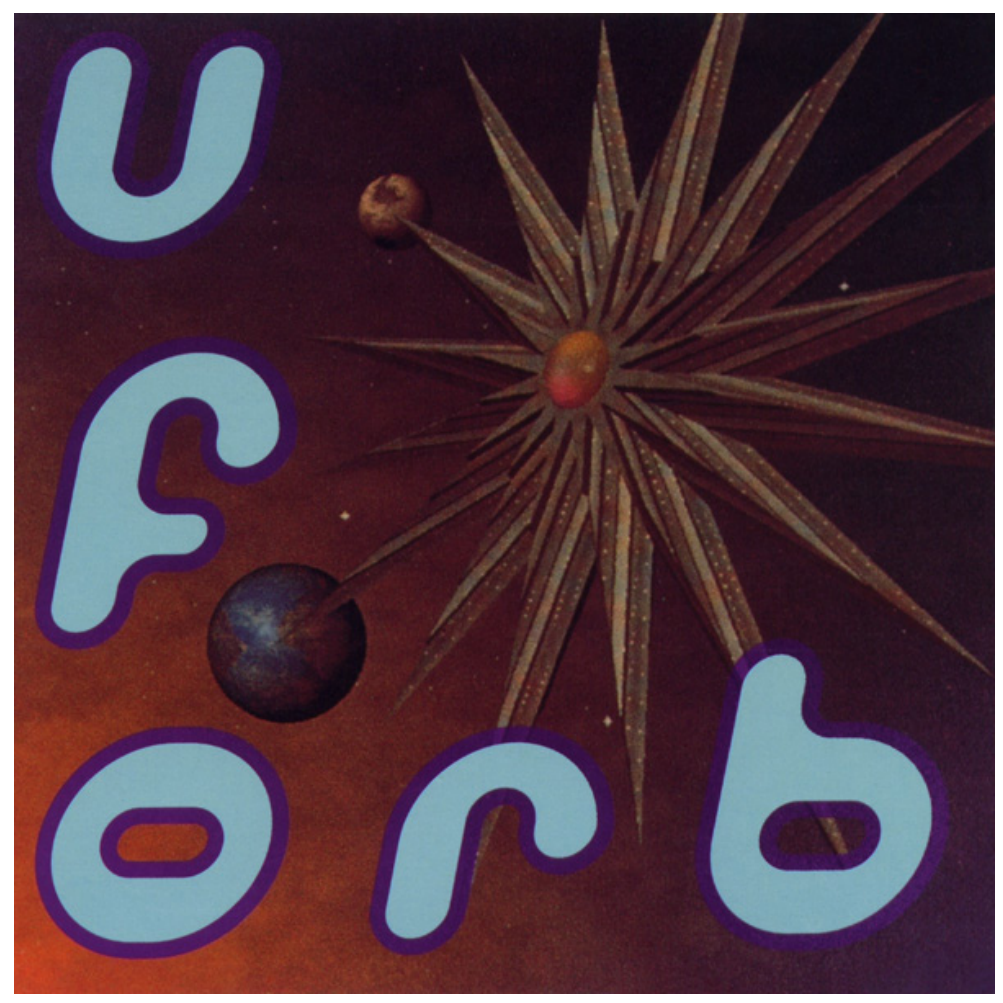

Figure 4. Cover art on The Orb's U.F.Orb, Island Red Label (1992). 
Their well known "Blue Room" (on Blue Room, 1992), named after the top secret room in Hangar 18 at the Wright-Patterson Air Base where the US government allegedly stores UFO crash remains, uses a recording from the 1965 Gemini 4 spacewalk, and their earlier Adventures Beyond The Ultraworld (1991) picks up Apollo program radio signals from "tranquility base" (on "Back Side Of The Moon"). In 1992, The Orb toured their album U.F.Orb with music scholar Rupert Till recalling how they had "a huge balloon as a projection screen, onto which they projected imagery including the Apollo space launch" as well as "rockets taking off". 10

Studio engineer and former bassist with Killing Joke and member of some thirty other acts including The Orb, Martin "Youth" Glover would be critical to the infusion of ambient dub in psychedelia, having launched the down-tempo label, Liquid Sound Design, in 1998 (a sub-label to his Dragonfly Records, the first psychedelic trance label). Ambient and trance-fusion act, Star Sounds Orchestra, whose debut Planets (1991) featured tracks named after all the planets in our galaxy, would foment an ethnodelia appealing to the trance machine. ${ }^{11}$ And one of the key carriers of the techno-cultural cosmo-liberationist aesthetic within psytrance is a progressive style which owes its sophisticated optimizations to the cosmic rock tradition, notably Pink Floyd, ${ }^{12}$ whose concerts screened footage of Apollo missions. As Ken McLeod (2003: 346) points out with regard to the cosmic musicians and the space program:

The impressive banks of keyboards, the complex myriad of knobs and dials associated with the analogue synthesizers of 1970s progressive rock . . . and the increasingly advanced and variegated number of electronic guitar effects, were roughly analogous to the advanced technology being developed and exploited in the real space program. Thus the fetishisation of technique, virtuosity and musical complexity, which marked much of this music, is mirrored in the complexity of its instrumentation and technology.

Surrounded by banks of equipment, turning dials, monitoring screens and gauges, artists within psychedelic electronic music genres were like navigators setting the course towards uncharted space; a cool, detached presence in command of the ship, the sensibility of the austere competent programmer embodied by contemporary DJs across all genres.

As already noted, deep space is a universal source of awe, its depths occulting mysteries of origin and destination, genesis and apocalypse, with the mid-twentieth century penetration of space providing an allegory for percipience, the penetration of the "final frontier", the journey into the mind. This adventurous frontier-crossing mentality notably championed by Timothy Leary, has endured among the privateers and experimentalists drawn to Goatrance, for whom NASA's Apollo space program held appeal in narrating the journey. While NASA was developing and harnessing science and technology with the purpose of launching humankind beyond the exosphere, in ways imitating their various forebears, psychedelic artists were repurposing audio technologies to enable exploration of inner space, the unconscious. Indeed, the space mission analogizes this process, where 
"mission control" (e.g. "Houston") signifies base ego, the rational consciousness from which explorers seek distance and with which they may experience patchy communications or oxygen supply crises while in "orbit" ("Houston, we've had a problem"). Thus Apollo dialogue, as reproduced on Juno Reactor's seminal Transmissions (1993), Astral Projection's The Astral Files (1996) and Trust in Trance (1996), or on Cybernetika's Nanospheric (2008), which reproduces flight dialogue from the perilous Apollo 13 mission, effects a drift into the unconscious, and the unknown, where adversities are overcome and anything is possible (see St John 2013a).

To reproduce inquiry from the mysterious atmospherics of "Aliens" by French outfit Total Eclipse (on their debut 12-inch Aliens / Sound Is Solid, 1994), who are these aliens? "Where do they come from?" and "What do they want?". For technicians temping on the space programs in the psychedelic diaspora, outer space is a fictional realm potentiating the transcendence of condition, even the human condition, perhaps any buman condition. As outer space enables one's freedom from complex historical, social and personal conditions, it swarms with alien "nations". As fantasies and phantoms are launched, hopes and fears projected, these fictions, these alien-nationalities, orbit the Earth like a million satellites beaming back uncanny data to programmer communities and receiver cults. And as they buzz the heavens or haunt our dreams these alien fictions communicate with one another, they mate and mutate. Hard "black and white" distinctions between millenarianismsAfrodiasporic and otherwise-seem pointless as, for one thing, sonic fictions are plagiarized and remixed over and again, and for another, there is no simple "black" and "white" alien divide here given the presence, for instance, of large numbers of Japanese and Brazilian producers and enthusiasts in the psychedelic continuum. It is certain that disparities in socio-economic opportunities, race prejudice and social exclusion condition the "freedoms" sought-including alienation/alien-ation — and the capacity to achieve these outcomes.

While alienation for the majority is the result of a composite of factors related to race, gender, sexuality and limited opportunities, for others it more approximates the lifestyle strategy of the self-exile who seeks departure from repressive conditions, and who is resourced enough to convert repression into leisure. The "astral traveller" with the universe, multiverse or hyperspace within reach, offers a portrait of the relatively affluent (typically) white male raised on a diet of progressive individualism and the promise of manifest destiny. What is more, psychedelic trance has had very few black producers and enthusiasts among its marginal-albeit-privileged population. ${ }^{13}$ Yet, as purported in the disctopian visions of producers, promoters and participants alike, ultimately, it is the music, and its primary sites of reception, that potentiate intertextualization, inter-alien contact. Across a variety of EDM cultures and their events, historically admitting those who seek freedom from manifold oppressions, the Mothership charts a familiar course across the cosmic threshold and into the unknown, the potent source of transformation. Indeed Eshun celebrates the capacity in Black Atlantic sonic artistry to abduct and mutate those whose sensoriums are exposed to its alchemy - a becoming-in-sonics, a private futurism, the innerspatializing of the mythstakes. 


\section{Flight Club: The Interplanetary INTERCorporeality MaChine}

WHILE ESHUN made a remarkable contribution to the study of Afrofuturism, a trajectory the study of which has been accused of leaving the body behind in extropian conceptual gymnastics, he holds that the posthumanist "rhythmscience" of which he is concerned is not disembodied, indeed he made out that "sound machines don't distance you from your emotions ... [they] make you feel more intensely, along a broader band of spectra than ever before in the 20 $0^{\text {th }}$ Century" (1998: 00[-002]). A discussion of kinaesthesia and "the sensory environment" of pressure (ibid. A[183]), is preceded by reference to electronic composers, notably Sun Ra, being "tone scientists" through which crowds are like an "instrument played by electronics". Sun Ra's work revealed that "music is the science of playing human nervous systems, orchestrating sensory mixes of electric emotions: the music of yourself in dissonance". Yet, in these attentions to those who "engineer new humans through electronics" (ibid: 09[161]), we learn little of the role of the impact of their science and engineering in the primary real estate of their affect-in the laboratory of the dance floor. The vibe is aborted, presumably in the departure from the "street" and the "soul" chaining the Afrodiaspora to the blues and preventing a cyborgian future. Besides a small paragraph headed "The Audience is a Medium" (ibid), sites of reception are disregarded in this momentous quest to master the sonic fiction. The departure from the social is revealed as a deliberate effort to exaggerate the impact of sonic fiction on individuals as "new sensory lifeforms" (ibid. A[183]). But in the flight from sociality, the dedication to chart the use, development and impact of sound "conceptechnics" overlooks the role of cultural performance in "the sensory environment". Sonic fiction is certainly read in front of one's home stereo, inside the woofered public-privacy of your wheels, and by public transportusing "headphonauts" (ibid. 07[133]), but the electrosonic is a fiction that is ultimately shared, performed in intercorporeal audio-tactile rooms of varying size and sound quality. Surely, the vibrant dance floor, whether the main deck or boiler room of the Mothership, is heaviest among the pressure "points of maximum rhythmic hyperdelia" (ibid. A[187]).

And so gravitation pulls us back on the dance floor, the gravity of which is confirmed through the way clubs, warehouse raves and dance festivals are commonly designed to replicate off-planetary or cosmic space, where the dance floor is the launchpad with DJs programming and/or initiating the launch sequences. The sensation of being off one's planet and out of one's mind, enhanced by an ever growing compendium of psychedelic or entheogenic astro-fuels, is variously sonified as, for example, in Earth Nation's ethereal sound bath, "Alienated" (from their debut 12-inch Alienated, 1994) or any of Hallucinogen's early work like "Alpha Centauri" (released on his first 12-inch Alpha Centauri / LSD, Dragonfly, 1994). This transportative socio-sonics is enhanced by video, décor, blacklight, 3D string art installations and other technologies of the senses. Amid the ultraviolet subsonic meteor storm and laser battle, one might detect DJs appearing as high-tech skywalkers, as with the shoulder and forearm robotics adopted by Swede Anders Nilsson (aka Andromeda), or as "grey"-inflected extraterrestrials, apparently the desired effect of the alien mask-wearing 
German guitar-trance act S.U.N. Project. More generally, "surrounded by a circular bank of blinking sound equipment supplemented by various laser lights and smoke effects", the DJ appears like an "otherworldly futuristic benefactor, controlling foreign, unfamiliar technology" (McLeod 2003: 351). Under strange light, some of these characters appear to be transmitting messages from off-world locations. ${ }^{14}$ While this image of singularity and control insinuates the Greek god and titular head of NASA's lunar program, the paroxysmal indeterminacy and saturnalian funk of the dance floor reeks of that other god who, alongside Apollo, inspired Nietzsche in The Birth of Tragedy to develop an influential heuristic for understanding polarity in Western civilization. With this tension in mind, Neil Disconaut, who had launched space raves for the Association of Autonomous Astronauts (1995-2000), radio checks direct from the dance floor on the "Dionysus Programme". He reports "sensations of 'rushing, of accelerating velocity, of the body tracing a line of flight and of leaving behind 'the real world' and establishing a direct connection with the wider universe". Kicking up some dust on the moonscape of European myth and folklore, a lunarscape that NASA can never touch, he communicates further that there are "clear parallels here with the effects on the body and the euphoric feelings of escaping gravity associated with 'lift off' by more traditional means". ${ }^{15}$

These are not Gagarin-esque solo-flights. With a constellation of mirror balls and starshower lighting effects, dance floors have long been imagineered as realms for "space" exploration and alien encounters, a design-intent traceable at least to the 1960s and psychedelic rock (e.g. London's UFO club), and would be carried by disco and funk in the 1970s. Opened in the old Henry Miller Theatre in Times Square in 1978, Zenon was one of the more audacious examples from that period. The club boasted a sixteen-channel sound system, and its owners hired Douglas Trumbull (creator of the special effects in Close Encounters of the Third Kind) to design a spaceship that would descend and hover over the heads of the dancers - a project that was ultimately found unworkable and aborted (Shapiro 2005: 215). The "obsession with space and the prog rock tendencies" characterizing Italodisco, would manifest at the "Cosmic Club" in Lazise between 1979 and 1984 (Shapiro 2005: 276), and by the late 1980s, the opulent mega-club Space opened in Ibiza. In the meantime, another UFO Club, this time fueled by acid house techno, landed in the vaults of a former department store in Mitte in 1988 (closing in 1990, and later reopening as Tresor) where young citizens of the reunifying Germany, occupying a no-man's-land between the East and West, were willingly abducted from state-run tyranny and corporate slavery. Soon after, the Space Club (subsequently the Warehouse) opened in Koln (see the film by Sextro and Wick 2008). As interplanetary ports and portals, such clubs would promote an internationalist aesthetic with attention to diverse sonic flavours. At club Megatripolis opening in mid-1990s in London club Heaven, Fraser Clark played with the idea, not far removed from Terence McKenna's novelty theory, that dance floor occupants were "tuning in" from the future. The mission objective of the Dionysian Programme unfolds. In intercorporealized flight clubs one performs the fiction of alienation, and the discovery of one's self is potentiated in the encounter with other habitués of the flow, space brothers and sisters if you will, who, like 
planets orbiting the self, are proximate and within reach. Thus the dance floor Mothership becomes a living-mythology enabling contact with those who are alien-or other-to one's self. In the landscape of the vibe, s/he who is "alien" is rendered a "friend".

Today, dance parties are off-world and multi-genred carnivals where participants enact sci-fi fantasies in which the alien dances among us. In the festal dancescapes of psyculture, the almond-eyed and vestigial alien is pervasive, a symbol of ultimate difference, which signifies at the same time the romantic will to transcend difference. This icon of otherness is, in McLeod's view (2003: 339), "capable of challenging simplistic binaries of male/female, black/white or rich/poor", with alien iconography enabling a "symbolic incorporation of the idealized, raceless, classless, and genderless plurality of the dance floor". Thus, in its emblematizing and erasure of difference, the archetypally benevolent alien is a utopic standard of unity, with aliens flying on banners at international psycultural and visionary arts festivals, embossed on textile fashions, digitized in website graphics and inhering in contagious logos, like flags under which all unite. ${ }^{16}$

\section{"ISRALIENS": SeEking ANOTHER World}

As mentioned at the beginning of this article, Israeli Goa outfit Power Source sampled Sun Ra from Space is the Place on their driving classic "Goaway". The group would later reproduce lines from the same source on their 1999 release "Skywalker" (Cosmic Waves): "It's the music of the Earth, the music of the Sun and the stars. The music of yourself.... Teleport the whole planet here, through music". Approaching Sun Ra as something of an alien guru, Israeli Kfir Shlomovitz (aka Space Monkey) later deployed the same material on the psybreaks departure "Flash-Daddy" from his debut Psychotic Episode (2004). Space is the Place is rare cinema combining director John Coney's lurid blaxploitation designs with Sun Ra's cosmic plans. The film's message is ambiguous, since Sun Ra initially announces his intentions to repatriate Earthlings to an exclusive off-world "colony for black people", though it emerges that non-African Americans (as far as I could tell, two white "hookers") are permitted to board the Mothership, and Sun Ra announces to one ship-bound passenger, the subservient Jimmy Fey, that he is to leave his "black parts" at the door (Sun Ra appears to be electing to absorb his "blackness"). In the Arkestra's final performance, before the Mothership launches from an exploding Earth, Sun Ra chants: "Your ignorance will be your salvation.... I will take you to new unseen worlds ... another world". Underlining Sun Ra's philosophy of embracing the unknown, the film echoes Star Trek and the early 1960s series The Twilight Zone. Yet, rather than replicating human folly in space, the Mothership is ultimately bound for a raceless future, a utopic alien-ation. 


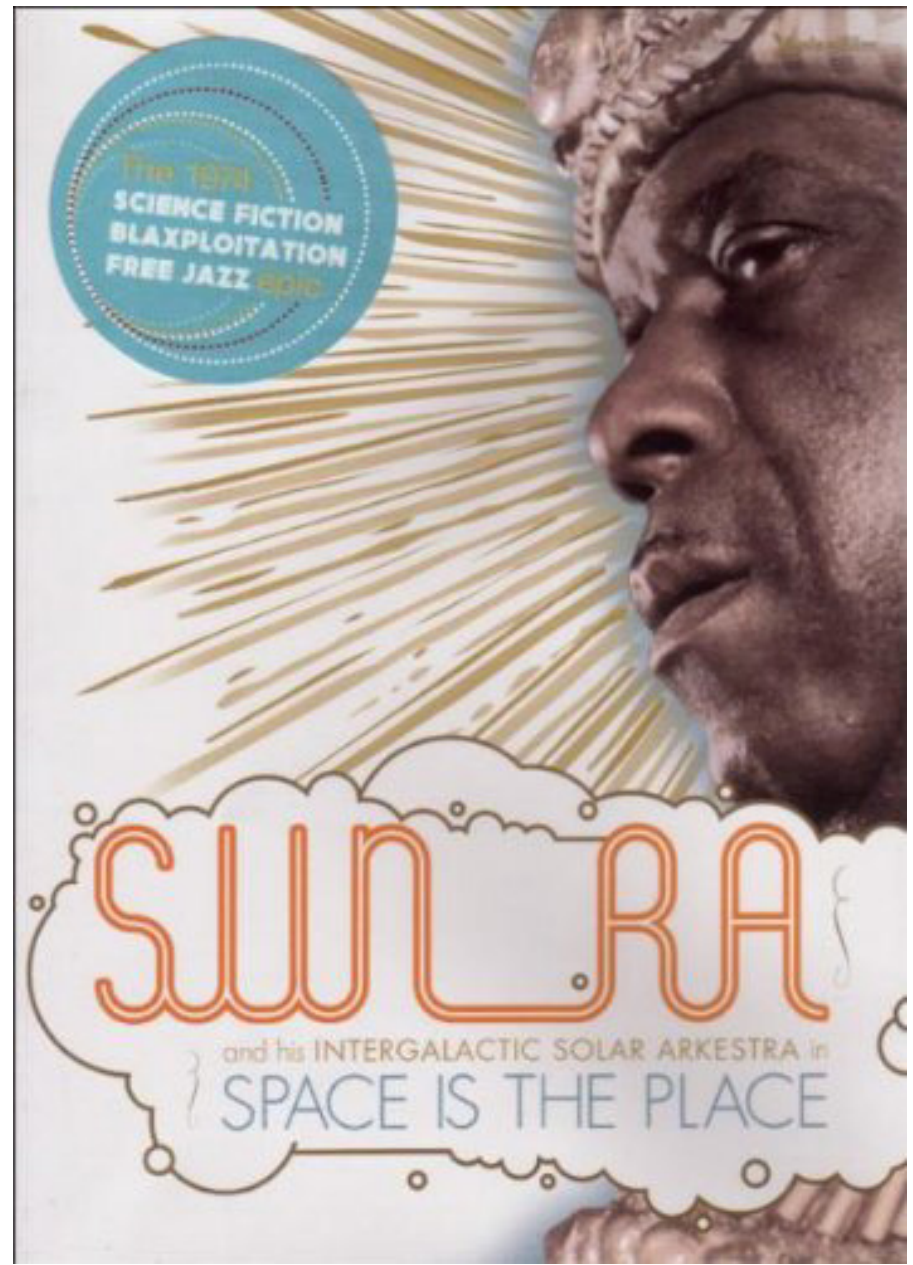

Figure 5. Video cover for John Coney's Space Is the Place. North American Star System (1974).

The mythos of the raceless unknown appears to suit disaffected Israeli trancistim - the term Israeli trancers use to identify themselves (see Schmidt 2010) - who made their entrance into psychedelic trance downstream from historical and social alienation. That is, it is appealing to those whose ancestors survived the Holocaust and established a Zionist state. But, more immediately, it appeals to young adults who, following mandatory military service and a tense upbringing, undertake a secular quest for another world, an alternate reality pursued in an outlaw, hyperliminal, techno-tribal lifestyle (see St John 2012d). Israeli Goatrance illustrates a penchant to decal the vibe with the promises inscribed in galactic travel, the alien encounter, with the designation "Israliens" ${ }^{17}$ striking appeal as a polysemous signifier, a hybrid term signifying both Israeli citizen and the outsider/ exile depicted in stylised homunculus iconography. An aestheticized "Sixties" appears to have affected Israelis in the late 1980s/early 1990s, with experience sought and obtained in the encounter with the other/otherness, including: foreign encounters (notably, in travels to Goa, Thailand, Japan and other destinations); sexual encounters (especially across ethnic/ 
racial lines); queer encounters (especially in a burgeoning gay and lesbian scene in Tel Aviv), virtual encounters (with the assistance of psychedelics and or entheogens); and alien encounters (curiously, many among those who have been abducted by aliens are regarded as "experienced": see Partridge 2003: 30). By the 1990s, a younger generation of Israelis were prepared to be abducted by and experienced in music, and their adoption of Afrofuturist aesthetic devices in which space was the place for the effacement of race reveals a mythos of unity in exile from historical trauma, a not insignificant tendency given that Israel possesses what is likely the highest population of psytrance producers and enthusiasts per-capita in the world. Indeed psytrance is popular music in Israel, a circumstance not replicated in any other country.

Following a three-year military service, young male and female Israeli adults experience temporary exodus from the permanent crisis at home via an international backpacking rite of passage (see Noy and Cohen 2005), perhaps enabling self-styled and luxurious reenactments of the myth of Abraham who, as Ken Goffman (2004: 12) notes, was "history's first self-exile". The protracted dimensions of this phenomenon have triggered considerable anxieties among critics as self-expatriation in trance obtains the character of a risk-laden lifestyle for youth as trancistim initially smuggled the Goa "state of mind" and guided the freak Mothership into the holy land (Taub 1997; Sagiv 2000). Though it should be recognized that rather than simply an import, the vibe of the (self) exile is endogenous to Israel, which is why Afrofuturist and other ascensionist discourse holds such appeal. Thus, we find the utopic project of one of the genre's most famous acts, Astral Projection-formed in 1995 by Israeli pioneers Avi Nissim, Lior Perlmutter and Yaniv Haviv ${ }^{18}$ - whose oeuvre is characterised by a quest for off-planetary becoming, as conveyed on storming tracks from the classic Trust in Trance release of 1996, like "People Can Fly", "Aurora Borealis" and "Utopia". The group's early anthem "Enlightened Evolution" (from the 12-inch by that name, 1996) used the memorable sample: "we have determined that the human form is best suited to our purposes". ${ }^{19}$ While it seems disingenuous to attribute sophisticated philosophical systems to artists based on short sound-bites, I suggest that their sonification indicates at least three connected implications: that Astral Projection were identifying themselves with raceless extraterrestrials; that they were committed to assisting the human condition; and that their art (their music) facilitates this evolution/abduction/becoming. That Astral Projection were fixated with cosmogenesis in which space was the stage for new beginnings was transparent in their classic "Let There be Light" (Orange Compilation, 1995), on which can be heard the critical lines from Genesis (the first book of the Old Testament), spoken by Apollo 8 NASA Lunar Module Pilot, William Anders, in his Christmas Eve 1968 broadcast from lunar orbit. Spoken against the vast background of open space, the narrative promises life flowering in an empty void. Within the dark vacuum of space, light becomes a source of hope. In this light, it is clear that outer space offered a blank canvas for the imagination, a topos upon which utopian fantasies were projected, fresh designs uploaded, new worlds populated. 


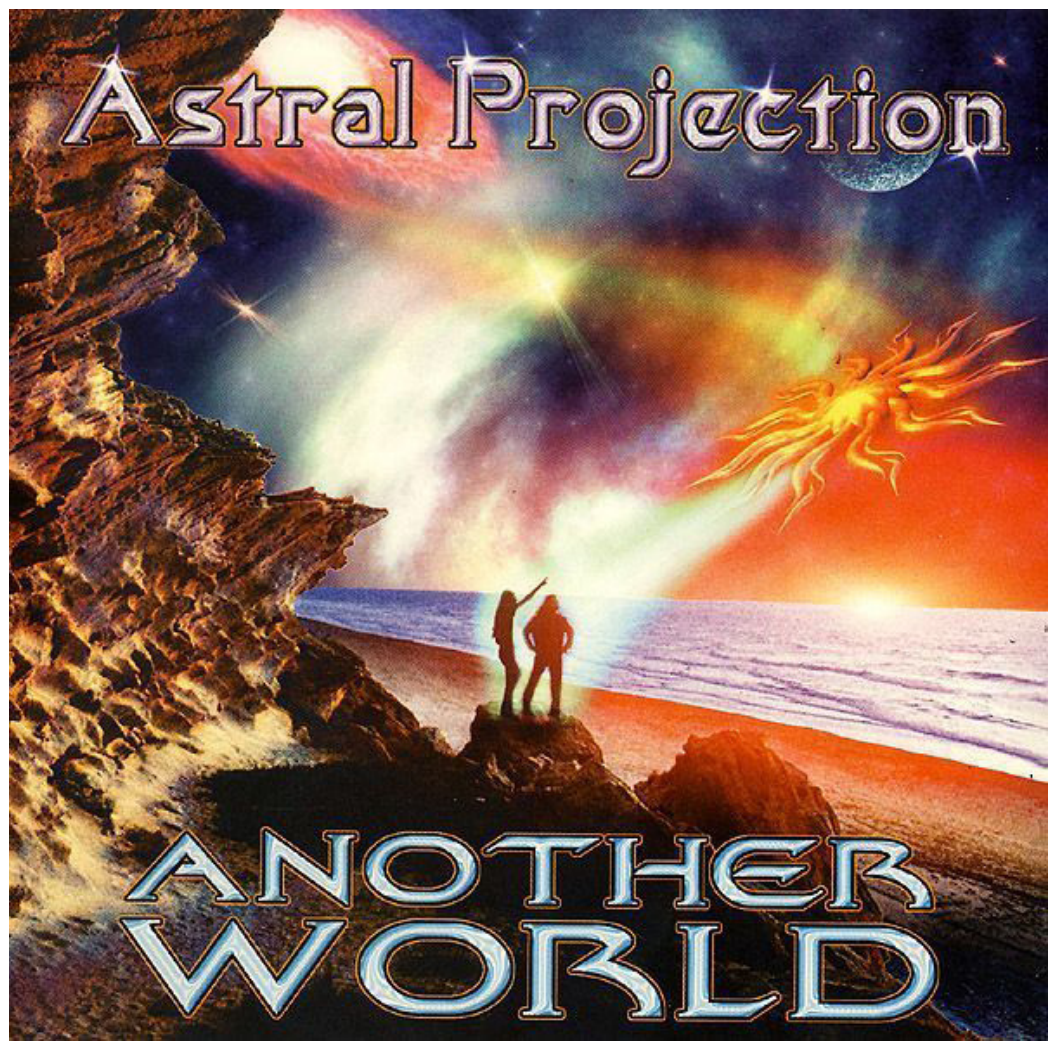

Figure 6. Cover art for Astral Projection's Another World. Trust in Trance Records (1999).

With Astral Projection and in many other Israeli Goa/psytrance acts, one finds evidence of a belief in a higher, or cosmic, purpose, in which those who are experienced, impart their wisdom to others in a messianic commitment to tinker with evolution, raise consciousness, revitalize humanity, save the Earth, generate new worlds, etc. This diverse mission is so often conveyed via the language of visitation, contact, abduction, as found in samples and, ultimately, music is the vehicle mastered by those who feel chosen to transport the trancefloor into a better world. Promoter Asher Haviv fits the bill here. In 1997, Haviv organized what was at that time the largest psychedelic trance festival in Israel and anywhere else: "Karahana: A Drugless Festival", so named as a way of successfully garnering the support from authorities to hold the event at Ganey Huga, a popular water park. The event attracted some 15,000 people, and Ori Gruder's film documentary of the event, Karahana (1998), promoted that the festival came "from outer space, from another dimension, with cosmic-hypnotic sounds came the trance-ship and landed in Israel. The super-computer chose the 'Drugless' festival as the place where the revolution will start". Here the party vibe is infused with the sensibility of the chosen, the elect, though clearly this is augmented by the messianic temperament of promoters like Haviv. And so, in 2007, the ground was once again cleared for the landing of the "trance-ship" at the Holy Rave at Timna National Park in the Arava Desert (at the site of a replica of the Ark of the Covenant) over Rosh Hashana 
(Jewish New Year). At Timna, Haviv struck the pose of a Moses-like figure shepherding the elect few on board his colossal Mothership towards the "light at the end of the desert". This cosmic salvation has its parallel in the work of Sun Ra who through an early mystical awakening experience-an alien abduction via "transmolecularization" to Saturnbelieved he was selected to undertake the redemption of his people and build the Arkestra. It is a project integral to psytrance, but is seemingly most advanced among the historical descendants of the "chosen people" as per the Old Testament, some of whom might see in Sun $\mathrm{Ra}$ a fellow exile. This is not in any way orthodox Judaism, yet sometimes artists become akin to channels of prophecy, such as MFG (Message From God) the group formed by Guy Zukrel and Aharon Segal, though the message more generally holds more in common with alternative spiritual perspectives inflected with Indian religion and philosophy, as partial and superficial as this often is. There is no evidence that these artists possess sustained "cosmic plans" like Sun Ra (or believe that the world necessarily faces immanent collapse), but psyculture is prominent in a terrestrial and "progressive millenarianism" (as opposed to an "apocalyptic millenarianism": see Wojcik 2003), where artists, promoters and enthusiasts respond to ecological cataclysm, economic disaster and social upheaval coincident with the end of the Mayan calendar cycle (see St John 2011b).

While holding inheritance from the off-world fantasies of Leary and Sun Ra, this is not a disembodied extropianism. Such is evident in Israel in the emergence of Full On, a mechanically funkipated chopper trance sound which would offer evidence that the declaration to "give up the funk" was being called for and getting a response. Here, one's experience, would be expressed less by one's movement through the astral planes or elevation into the mathematics of universal sound, but grounded in the swing, the funk, the groove. Not a cerebral space-time continuum occupied by prog-psy participants, but a tribal bootytime illogicality, a trajectory also undertaken within the electro and tech-house aesthetics pulsating through psychedelic trance in the first decade of the 2000s. Indeed, the black body, a veritable spacepimp, is sometimes deployed as a signifier. Take, for instance, Psysex's Come in Peace (2003), a funked-up and over-sexed space-romp the title track on which features the memorable line "bro was On!" Incidentally, the album's title revises the famed Apollo 11 narrative employed on Dance 2 Trance's early 1990s anthem "We Came in Peace" released on a 1991 self-titled maxi-single (the cover of which features a B\&W close-up of an open helmeted astronaut). While NASA dialogue was used to convey a peaceful message at an historical juncture in which the Iron Curtain was raised and Apartheid dismantled, over ten years later, with the "come" in the title adapted to convey orgasm, if there was a line between abduction and seduction, the astral and the orgasmic, it had grown fuzzier. With the post-Goa electro-express carrying strains of cosmopolitanism and miscegenation subverting dominant sexual and racial categories, a funky ambience pervaded psyculture by the first decade of the $21^{\text {st }}$ century, with growing numbers of artists joining the electroinfluenced progressive house party. Labels like Blue Tunes Recordings and the work of producer/DJs like Feuerhake or Fusco, for example, illustrate that the "progressive" edge of psychedelia is partially shaped by the demand for the electro pulse. ${ }^{20}$ 
The growth of psychedelic electro-funk may signify the return from the astronautical discharge of Goatrance, the cosmic heights of which have nevertheless enabled extraordinary vistas and critical readouts momentous to "ground control", the self, the Earth. Keen pirates of Apollo dialogue, Astral Projection's seminal release (The Astral Files, 1996) "Zero" marks that moment of ejaculatory blast-off where the crew of Apollo 8 have completed their count down, initiated launch sequence, and cleared the tower. At maximum thrust "Houston" reads the voyagers "loud and clear". The December 1968 Apollo 8 mission was the first manned space voyage to escape the Earth's gravitational field. The story was taken up on Astral Projection's second CD release, with the only words on the track "Black And White" being retrospective commentary from mission Commander Frank Borman: "And the view of the Earth, it was the only place in the universe that had any color. Everything else was black and white" (Trust In Trance, 1996). The comments speak to what has been identified as the greatest revelation of the Apollo missions-which derived not from rocks gathered on the moon, but from Earth, the appearance of which over the lunar horizon startled Borman and his crew, the first humans to witness planet Earth from the lunar orbit (literally from the "dark side" of the moon). Indeed the "Earthrise photograph" taken at that time by astronaut Bill Anders would become arguably the most important photograph ever taken. The image of a blue globe, small and vulnerable in the vastness of space was, according British space historian Robert Poole, "an epiphany in space ... a rebuke to the vanity of humankind" (McKie 2008). Offering what has been referred to as the "Overview Effect", "Earthrise" would provide the stimulus for the "Gaia hypothesis" and inspire the popular expression of ecological and humanitarian concerns. The revelation captivated many Goa/ psytrance producers, promoters and boosters, the movement giving rise to festivals which would instrumentalise a planetary vibe aboard spaceship Earth. Karahana offered an earlier model for this type of experience, but it would be the international total solar eclipse festivals emerging from the mid-1990s (see St John 2013c), and transnational festivals like Australia's Exodus, Portugal's Boom, or Brazil's Universo Parallelo, each attracting thousands from a multitude of countries, that would continue to be significant in this regard. These events are known for their lateralized accommodation of genred multitudes, perhaps none more so than Boom, which in its fifteen years, has evolved into a weeklong biennial climax in which, in 2012, some $25,000+$ people (from over one hundred countries) participated.

\section{"Teleport the Whole Planet Here"}

THIS ARTICLE has begun the daunting task of charting the vibe of the exiles. Furnished with futurist fantasies and imagined as a cosmopolitan Mothership, programmed to enable public utopias and private parties, within psyculture, downstream from Goatrance and psytrance, this socio-sonic aesthetic is conceptualized with the assistance of Space Age programs, science fiction cinema and administered with multiple sonic genres. In its optimized state, the vibe is a fusional context, an orgiastic temporality conditioned by a remix aesthetic involving the recombination of psycho-integrators, sonic debris and popular cultural artifacts. Existential communitas has been a lasting feature of psyculture 
from its inception, whose "mothership connections" and astral projections are grounded in Romantic-ascensionist and Afrofuturist psyconceptechnics. While it is clear that variant histories and patterns of economic and socio-political alienation have conditioned the fabulous fictions and indubitable revelations of alienation/alien-ation, in the history of EDMC, the dance floor vibe is both the launching pad to, and the landing zone for, other subjectivities and worlds. Akin to cosmic rock and space jazz in which we can trace its roots, Goatrance emerged as a hyper-transitional fusional movement embracing the trope of space exploration as a narrative of metamorphosis, and, concomitantly, the alien as a stylistic device, signifying, as McLeod similarly conveyed for raves, a utopic desire to transit to "a common 'other' transcending divisions of race, gender, sexual preference, religion or nationality" (2003: 354). Such pretensions are doubtlessly idealist. After all, Arun Saldanha (2007) has outlined a tendency in Goa where domestic tourists are held by party-goers to dilute the purity of the "freak" nation, and researchers of Israeli trance have observed a tendency among middle-class Ashkenazim to exclude from mesibot those who are not "beautiful people", nominally lower-class Eidot Ha'mizrax or Jews of North African or Middle Eastern descent (Meadan 2001: 35, 44; Schmidt 2010). Such may be elitist, or even racist, attitudes towards ethnic "aliens", yet it should be recognized that undesirables subject to exclusions are sometimes noted for their predatory and offensive behaviour towards female participants, which is an observation made by Schmidt and supported by my own observations. This serves to illustrate that "freedoms" pursued within the domain of the EDM vibe are heterogeneous, that it is inhabited by parties differentially committed towards its success. Within the complex psychedelic imaginary, the alien is desirable and liberating, albeit intercepted along different orbits. Thus, cosmic utopias and extraterrestrial exotica of Afrodiasporic "alien abductees", "Israliens" and other home-seeking astral-travelers are defined according to differential historical oppressions, contemporary traumas and personal life-world circumstances. Psyculture luminaries continue to build Freak Arkestras whose mechanics of transcendence and mythos of universality may be as utopian as Sun Ra's vision. Yet, their inspiration has seen the emergence of spectacular sonicities whose precincts hum with cultural and sonic diversity. And their imperative, like that of Sun Ra and other agents in the Afrofuturist pantheon, is to tweak the perennial groovebox, effect the vibrations and optimize the vibe in the pursuit of an alternate reality.

\section{NOTES}

1 Following linguist David Dalby, Leland traces "hip", and thus "hippie", to the Wolof language of slaves from the West African nations of Senegal and coastal Gambia among whom hipi meant "to open one's eyes". Additionally jive is rooted in jev, meaning "to disparage or talk falsely", and dig is rooted in dega, "to understand" (see Leland 2004: 5-6).

2 In which innovators Beppe Loda and Daniele Baldelli figured strongly. Loda used the phrase "elettronica meccanica" to describe his music mixing, and used the word "Afro" and later "freestyle" to describe his mix tapes and selections partly inspired by African/tribal music and "afrobeat" (Campbell 2007). Baldelli played diverse selections of classical, African and Brazilian folk, and synth-pop from the late 1970s through mid-1980s (Wang 2005). 
3 The organizers of Portugal's Boom Festival report that passport holders from over 100 different nations attended the festival in 2012.

4 While many examples could be provided here I can only mention a few: Loopus in Fabula's funkadelic mission; breaks going astral care of Deviant Electronics, Syncro and other psybreaks pioneers; and psychedelic dubmeisters Youth and Ott.

5 Much of the charting of inner/outer space has been conducted with the assistance of psychedelics and "entheogens", a theme explored, for example, in Rick Strassman et al (2008).

6 The constant changing titles for Sun Ra's Arkestra (e.g. Solar Myth Arkestra, Blue Universe Arkestra and Jet Set Omniverse Arkestra) is a good example of this.

7 With the sampled transmission from Black Panther Party cofounder Huey P. Newton (e.g. "The spirit of the people is greater than man's technology") on "Lost Transmission From Earth", this work does not deviate from UR's militant trajectory.

8 Cydonia is a region of Mars achieving notoriety after images taken by the Viking orbiters in 1976 were sent back to Earth revealing an apparent human face and pyramidal rock formations.

9 The title holds an allusion to Public Enemy's Fear Of A Black Planet (1990).

10 Rupert Till, email to the author, 7 April 2009.

11 Still sought-after in the psychedelic electronic festival circuit, SSO would become renowned for producing "cosmically tuned" music; that is, music produced according to the calculations of the Cosmic Octave developed by Hans Cousto, which recognizes that each planet holds its own specific frequency, rhythm and color. The idea inspired the signature "Cosmic Gong" developed by SSO member Jens Zygar and Cousto. The 1995 album Inter Planetary Ambience (Live In London) (i.t.p. recordings) features "a complete musical journey through the planetary tunings of our solar system" (from sleeve).

12 Pink Floyd are known to have produced one of the first electronic psychedelic tracks, "On the Run" (The Dark Side Of The Moon, 1973).

13 This assertion is consistent with the views of Artur Soares Da Silva, an organiser of Portugal's Boom Festival, who informed me that psytrance "is the only dance music that was originated with no 'black' people involved from the scratch". He stated that while descendents of former Portuguese colonies, Cape Vert, Guine-Bissau and Angola, have been involved in Boom from the beginning, their numbers are small, mainly from middle class backgrounds, and quite a few "from families of politicians or military". He further stated that about 100 people of African descent were present at the 2008 Boom Festival, estimated to attract 25,000 people (Artur Soares Da Silva, email communication, April 30, 2009).

14 Perhaps not as far-fetched as it seems, if Kenji Williams fulfils his desire to be the first person to DJ to dance floors on Earth from its orbit, a desire he communicated to me in interview on Limnos, Greece, in 2007.

15 “Take a Dancing Flight”. Newsletter of Disconaut AAA (Association of Autonomous Astronauts) < http://www.uncarved.org/disconaut/dnaut2.html $>$.

16 While in iconography and sonic graffiti the benevolent alien offers a potent utopian icon of hope and unity, there is evidence (e.g. within "dark trance" productions) of the malevolent alien other forecasting decidedly dystopian futures and a fear of the unknown.

17 As, for instance seen on the Israliens compilation series released by HOM-Mega. 
18 All previously involved with techno/Goatrance project SFX (along with Guy Sebbag).

19 It was the voice of The Invid Regess lifted from the episode "Reflex Point" on the final series of the mid-1980s Robotech series, which, incidentally, augured the spread of Japanese anime in the West.

20 The La Boum compilation (2009) holds interest here given that the cover features an image of a supersized 1970 s afro bust with sunglasses.

\section{REFERENCES}

Adinolfi, Francesco. 2008. Mondo Exotica: Sounds, Visions, Obsessions of the Cocktail Generation.

Trans. Karen Pinkus with Jason Vivrette. Duke University Press.

Campbell, Jeremy. 2007. "Interview with DJ Loda”. Discopia, August 19.

D’Andrea, Anthony. 2007. Global Nomads: Techno and New Age as Transnational Countercultures. New York: Routledge.

Dery, Mark. 1993. "Black to the Future: Interviews with Samuel R. Delany, Greg Tate, and Tricia Rose”. South Atlantic Quarterly 94 (4): 735-78.

Davis, Erik. 1998. Techgnosis: Myth, Magic and Mysticism in the Age of Information. Harmony Books.

- - - 2002. "Recording Angels: The Esoteric Origins of the Phonograph". In Undercurrents:

The Hidden Wiring of Modern Music, ed. Rob Young, 15-24. New York: Continuum.

Elliott, Luther. 2010. "Goa is a State of Mind: On the Ephemerality of Psychedelic Social

Emplacements”. In The Local Scenes and Global Culture of Psytrance, ed. Graham St John, 21-39. New York: Routledge.

Eshun, Kodwo. 1998. More Brilliant than the Sun: Adventures in Sonic Fiction. London: Quartet.

Fikentscher, Kai. 2000. "You Better Work!" Underground Dance Music in New York City. Hanover: Wesleyan University Press.

Goffman, Ken. 2004. Counterculture Through the Ages. New York: Villard Books.

Heelas, Paul and Linda Woodhead, with Benjamin Seel, Bronislaw Szerszynski and Karin

Tusting. 2005. The Spiritual Revolution. Why Religion is Giving Way to Spirituality. Oxford:

Blackwell.

Hollings, Ken. 2002 “The Solar Myth Approach. The Live Space Ritual: Sun Ra, Stockhausen, P-Funk, Hawkwind”. In Undercurrents: The Hidden Wiring of Modern Music, ed. Rob Young, 99-111. New York: Continuum.

Katz, David. 2000. People Funny Boy: The Genius of Lee "Scratch" Perry. Canongate.

Lawrence, Tim. 2003. Love Saves the Day: A History of American Dance Music Culture, 19701979. Durham: Duke University Press.

- - - 2008. "Disco Madness: Walter Gibbons and the Legacy of Turntablism and Remixology”. Journal of Popular Music Studies 20 (3): 276-329.

Leary, Timothy, Ralph Metzner and Richard Alpert. 1964. The Psychedelic Experience: A Manual Based on the Tibetan Book of the Dead. New Hyde Park: University Books.

Leland, John. 2004. Hip: The History. New York: Ecco Press.

Lindop, Robin. 2010. "Re-evaluating Musical Genre in UK Psytrance”. In The Local Scenes and Global Culture of Psytrance, ed. Graham St John, 114-30. New York: Routledge. 
Mailer, Norman. 1957. “The White Negro: Reflections on the Hipster”. Dissent 4: 276-93.

Malyon, Tim. 1998. "Tossed in the Fire and They Never Got Burned: The Exodus Collective". In DIY Culture: Party and Protest in Nineties Britain, ed. George McKay, 187-207. London: Verso.

McKay, George. 1996. Senseless Acts of Beauty: Cultures of Resistance Since the Sixties. London: Verso.

- - - ed. 1998. DIY Culture: Party and Protest in Nineties Britain. London: Verso.

McLeod. Ken. 2003. "Space Oddities: Aliens, Futurism and meaning in Popular Music”. Popular Music 22: 337-55.

Meadan, Bryan. 2001. TRANCENational ALIENation. Trance Music Culture, Moral Panics and Transnational Identity in Israel. Lulu.

Nisbet, Thomas. 2005. "Planet Rock: Black Socioreligious Movements and Early 1980s Electro" In Call Me the Seeker: Listening to Religion in Popular Music, ed. Michael J. Gilmour, 226-38. New York: Continuum.

Noy, Chaim and Erik Cohen, Eds. 2005. Israeli Backpackers: From Tourism to a Rite of Passage. New York: State University of New York Press.

Partridge, Christopher. 2003. “Understanding UFO Religions and Abduction Spiritualities”. In UFO Religions, ed. Christopher Partridge, 3-42.

London: Routledge.

- - - 2004. The Re-Enchantment of the West: Alternative Spiritualities, Sacralization and Popular Culture and Occulture. Volume 1. London: T \& T Clark International.

_- _. 2007. "King Tubby Meets the Upsetter at the Grass Roots of Dub: Some Thoughts on the Early History and Influence of Dub Reggae”. Popular Music History 2 (3): 309-31.

Reynolds, Simon. 1997. "Return to Eden: Innocence, Indolence and Pastoralism in Psychedelic Music, 1966-1996". In Psychedelica Britannica: Hallucinogenic Drugs in Britain, ed. Antonio Melechi, 143-65. London: Turnaround.

Rietveld, Hillegonda. 2008. "Embodied Technocracies". Conference Paper. Panel on Uncertain Vibes: Tension, Contrast and Change in Electronic Dance Music Cultures. ACS Crossroads in Cultural Studies. Kingston, Jamaica.

Sagiv, Assaf. 2000. "Dionysus in Zion". Azure 9 (Spring). < http://www.azure.org.il/magazine/ magazine.asp?id=142> (accessed 1st September 2009).

Saldanha, Arun. 2007. Psychedelic White: Goa Trance and the Viscosity of Race. Minneapolis: University of Minnesota Press.

Schmidt I. Joshua. 2010. “(En)Countering the Beat: Paradox in Israeli Psytrance”. The Local Scenes and Global Culture of Psytrance, ed. Graham St John, 131-48. New York: Routledge.

Shapiro, Peter. 2005. Turn the Beat Around: The Secret History of Disco. New York: Faber and Faber. Silcott, Muriel. 1999. Rave America: New School Dancescapes. Quebec: ECW Press.

Sinker, Mark. 1992. "Loving the Alien / In Advance of the Landing". WIRE: Adventures in Modern Music. \# 96 (Feb).

Slater, Howard. 2006. "Lotta Continua: Roots Music and the Politics of Production”. Datacide 9 (May). <http://datacide.c8.com/lotta-continua > (Accessed 1 September 2009).

Sommer, Sally. 2001-2. "C'mon to my House: Underground-House Dancing”. Dance Research Journal 33 (2): 72-86.

St John, Graham, ed. 2001. FreeNRG: Notes From the Edge of the Dance Floor. Melbourne: Common Ground. 
_- _. 2004. “The Difference Engine: Liberation and the Rave Imaginary”. In Rave Culture and Religion, ed. Graham St John, 19-45. London: Routledge.

_-_. 2009. Technomad: Global Raving Countercultures. London \& Oakville, CT: Equinox Publishing.

-_-. 2011a. "DJ Goa Gil: Kalifornian Exile, Dark Yogi and Dreaded Anomaly”. Dancecult: Journal of Electronic Dance Music Culture 3(1). 97-128.

-_- 2011 b. “The 2012 Movement, Visionary Arts and Psytrance Culture”. In 2012: Decoding the Countercultural Apocalypse, ed. Joseph Gelfer, 123-43. Sheffield \& Bristol, CT: Equinox Publishing.

- - - 2012a. Global Tribe: Technology, Spirituality and Psytrance. Sheffield \& Bristol, CT: Equinox Publishing.

_- - 2012b. "Seasoned Exodus: The Exile Mosaic of Psyculture”. Dancecult: Journal of Electronic Dance Music Culture 4(1): 4-37.

-_-. 2012c. "Experience, Tribalism and Remixology in Global Psytrance Culture". In What Matters? Ethnographies of Value in a Not So Secular Age, eds. Courtney Bender and Ann Taves, 248-75. New York: Columbia University Press.

-_- 2012d. "Freak Media: Vibe Tribes, Sampledelic Outlaws and Israeli Psytrance". Continuum: Journal of Media and Cultural Studies. 26 (3): 437-47.

_- _. 2013a. "Aliens Are Us: Cosmic Liminality, Remixticism and Alienation in Psytrance". Journal of Religion and Popular Culture. 25 (2): 186-204.

_- _ 2013b, "Goatrance Travellers: Psytrance and its Seasoned Progeny". In The Globalization of Musics in Transit: Musical Migration and Tourism, eds. Simone Krüger and Ruxandra Trandafoiu, 160-81. New York: Routledge.

_- - 2013c. “Total Solar Eclipse Festivals, Cosmic Pilgrims and Planetary Culture”. In Pop Pagans: Pagans and Popular Music, eds. Donna Weston and Andy Bennett, 126-44. Durham: Acumen.

Strassman, Rick with Slawek Wojtowicz, Luis Eduardo Luna and Ede Frecska, eds. 2008. Inner Paths to Outer Space: Journeys to Alien Worlds through Psychedelics and Other Spiritual Technologies. South Paris: Park Street Press.

Sylvan, Robin. 2002. Traces of the Spirit: The Religious Dimensions of Popular Music. New York: New York University Press.

Szwed. John, F. 1998. Space Is The Place: The Lives and Times of Sun Ra. Cambridge: Da Capo Press.

Taub, Gadi. 1997. A Dispirited Rebellion: Essays on Contemporary Israeli Culture. Tel Aviv: Hakibutz Hameuchad.

Toop, David. 1984. The Rap Attack: African Jive to New York Hip Hop. Boston: South End. Turner, Fred. 2006. From Counterculture to Cyberculture: Stewart Brand, the Whole Earth Network, and the Rise of Digital Utopianism. Chicago: University of Chicago Press.

Turner, Victor. 1967. "Betwixt and Between: the Liminal Period in Rites de Passage". In The Forest of Symbols: Aspects of Ndembu Ritual (Victor Turner anthology), 93-111. Ithaca: Cornell University Press.

Wang, Daniel. 2005. "Interview with Baldelli”. Discopia \#3, May.

Weheliye, Alexander. 2002. “Feenin': Posthuman Voices in Contemporary Black Popular Music”. Social Text 71, 20 (2): 21-47. 
Wojcik, Daniel, 2003. "Apocalyptic and Millenarian Aspects of American UFOism”. UFO Religions, ed. Christopher Partridge, 274-300. London: Routledge.

Zuberi, Nabeel. 2004. "The Transmolecularization of [Black] Folk: Space is the Place, Sun Ra and Afrofuturism". Off the Planet: Music, Sound and Science Fiction Cinema, ed. Philip Hayward, 77-95. London: John Libbey Publications.

\section{DISCOGRAPHY}

Afrika Bambaataa \& Soulsonic Force. 1982. Planet Rock. Tommy Boy Music (Vinyl, 12-inch): TB 823. <http://www.discogs.com/Afrika-Bambaataa-the-Soul-Sonic-Force-Planet-Rock/ release/2047>.

Afrika Bambaataa \& Soulsonic Force. 1986. Planet Rock - The Album

Tommy Boy Music (Vinyl, LP): TBLP 1007. <http://www.discogs.com/

Afrika-Bambaataa-Soulsonic-Force-Planet-Rock-The-Album/release/98021>.

Asia 2001. 1997. Psykadelia. Trans'Pact Productions (CD): 097-008. <http://www.discogs.com/Asia-2001-Psykadelia/release/238790>.

Astral Projection. 1996. Enlightened Evolution. TIP Records (Vinyl, 12-inch): TIP 010. $<$ http://www.discogs.com/Astral-Projection-Enlightened-Evolution/release/17693 >.

Astral Projection. 1996. The Astral Files. Trust In Trance Records (CD): T.I.T.CD008. http://www.discogs.com/Astral-Projection-The-Astral-Files/release/44980>.

Astral Projection. 1996. Trust In Trance. TIP Records (CD): TIPCD5. http://www.discogs.com/Astral-Projection-Trust-In-Trance/release/41508 >.

Astral Projection. 1997. Dancing Galaxy. Ganesha (CD): GAN-02. <http://www.discogs.com/Astral-Projection-Dancing-Galaxy/release/20570>.

Astral Projection. 1999. Another World. Trust In Trance Records (CD): T.I.T. CD 019. <http://www.discogs.com/Astral-Projection-Another-World/release/15581 >.

Coltrane, John. 1965. Ascension (edition I). Impulse! (Vinyl, LP): AS-95. <http://www.discogs.com/John-Coltrane-Ascension-Edition-I/release/532432>.

Coltrane, John. 1965. Meditations. Impulse! (Vinyl, LP): AS-9110. <http://www.discogs.com/John-Coltrane-Meditations/release/885346>.

Coltrane, John. 1967. Om. Impulse! (Vinyl, LP): AS-9140. <http://www.discogs.com/John-Coltrane-Om/release/928106>.

Coltrane, John. 1968. Cosmic Music. Impulse! (Vinyl, LP): AS-9148. < http://www.discogs.com/John-Coltrane-Alice-Coltrane-Cosmic-Music/release/1885299>.

Coltrane, John. 1974. Interstellar Space. Impulse! (LP): ASD-9277. <http://www.discogs.com/John-Coltrane-Interstellar-Space/release/933890>.

Cybernetika. 2008. Nanospheric. Self-released (MP3 Album). <http://www.discogs.com/Cybernetika-Nanospheric/release/1650669>.

Cydonia. 1997. Mind Hunter. Blue Room Released (CD, Maxi-Single): BR061CD. <http://www.discogs.com/Cydonia-Mind-Hunter/release/75760>.

Cydonia. 1999. In Fear of A Red Planet. Blue Room Released (CD): BR079CD. <http://www.discogs.com/Cydonia-In-Fear-Of-A-Red-Planet/release/35817>. 
Dance 2 Trance. 1991. Dance 2 Trance. Suck Me Plasma (CD, Maxi-Single): SUCK TWO CD. < http://www.discogs.com/Dance-2-Trance-Dance-2-Trance/release/257262 >.

Earth Nation. 1994. Alienated. Eye Q Records (Vinyl, 12-inch): 4509 95485-0. <http://www.discogs.com/Earth-Nation-Alienated/release/10460>.

Eno, Brian (with Daniel Lanois \& Roger Eno). 1983. Apollo - Atmospheres \& Soundtracks. E'G Records (Vinyl, LP): 813 535-1. < http://www.discogs.com/ Brian-Eno-With-Daniel-Lanois-Roger-Eno-Apollo-Atmospheres-Soundtracks/ release $/ 72002>$.

Funkadelic. 1979. Uncle Jam Wants You. Warner Bros. Records (Vinyl, LP): WB 56712. $<$ http://www.discogs.com/Funkadelic-Uncle-Jam-Wants-You/release/101480>.

Hallucinogen. 1994. Alpha Centauri / LSD. Dragonfly Records (Vinyl, 12-inch): BFLT 14. <http://www.discogs.com/Hallucinogen-Alpha-Centauri-LSD/release/96507>.

Hallucinogen. 1997. The Lone Deranger. Twisted Records (CD): TWSCD1. $<$ http://www.discogs.com/Hallucinogen-The-Lone-Deranger/release/20583 >.

Jimmy Hendrix Experience, The. 1967. Are You Experienced. Track Records (Vinyl, LP, Mono): RS 6261. < http://www.discogs.com/Jimi-Hendrix-Experience-Are-You-Experienced/ release $/ 993028>$.

Juno Reactor, 1993. Transmissions. NovaMute (CD): NoMu 24 CD. <http://www.discogs.com/Juno-Reactor-Transmissions/release/2262>.

Kraftwerk. 1977. Trans-Europe Express. King Klang (Vinyl, LP): 1C 064-82 306. <http://www.discogs.com/Kraftwerk-Trans-Europa-Express/release/75547>.

La Boum. Compiled by NOK. 2009. Blue Tunes Recordings (CD, COMP): BTRCD026. <http://www.discogs.com/NOK-La-Boum/release/1740588>.

Martian, The. 1992. Meet The Red Planet. Red Planet (Vinyl, 12-inch): RP-1. <http://www.discogs.com/Martian-Meet-The-Red-Planet/release/7042>.

Martian, The. 1993. Cosmic Movement / Star Dancer. Red Planet (Vinyl, 12-inch): RP-2. $<$ http://www.discogs.com/Martian-Cosmic-Movement-Star-Dancer/release/2126>.

Model 500. 1985. No UFOs. Metroplex (Vinyl, 12-inch): M-001. <http://www.discogs.com/Model-500-No-UFOs/release/1300331 >.

Orange Compilation. 1995. TIP Records (CD, COMP): TIP CD 02. <http://www.discogs.com/Various-Orange-Compilation/release/33089>.

Orb, The. 1991. The Orb's Adventures Beyond The Ultraworld. Big Life (2 x CD): BLRDCD 05.<http://www.discogs.com/Orb-The-Orbs-Adventures-Beyond-The-Ultraworld/ release $/ 13265>$.

Orb, The. 1992. Blue Room. Logic Records (CD Maxi-single): 74321107022. <http://www.discogs.com/Orb-Blue-Room/release/13933>.

Orb, The. 1992. U.F.Orb. Island Red Label (CD): 162-535 006-2. <http://www.discogs.com/Orb-UFOrb/release/2728 >.

Overlords, The. 1994. All The Naked People. Arista (CD): 72445-11083-2. <http://www.discogs.com/Overlords-All-The-Naked-People/release/619233>.

Pink Floyd. 1973. The Dark Side Of The Moon. Harvest (Vinyl, LP): SHVL 804. <http://www.discogs.com/Pink-Floyd-The-Dark-Side-Of-The-Moon/release/1873013>. 
Power Source. 1996. Goaway. Matsuri Records (Vinyl, EP): MP16 <http://www.discogs.com/Power-Source-Goaway-EP/release/58786>.

Power Source. 1999. Cosmic Waves. Melodia Records (CD): MR 1010. <http://www.discogs.com/Power-Source-Cosmic-Waves/release/112591>.

Psysex. 2003. Come In Peace. HOM-Mega (CD): HMCD31. <http://www.discogs.com/Psysex-Come-In-Peace/release/219682>.

Public Enemy. 1990. Fear Of A Black Planet. Def Jam Recordings (CD): CK 45413. <http://www.discogs.com/Public-Enemy-Fear-Of-A-Black-Planet/release/458988>.

Shpongle. 1998. Are You Shpongled? Twisted Records (CD): TWSCD4. <http://www.discogs.com/Shpongle-Are-You-Shpongled/release/27195>.

Shpongle. 2005. Nothing Lasts... But Nothing Is Lost. Twisted Records (CD): TWSCD28. $<$ http://www.discogs.com/Shpongle-Nothing-Lasts-But-Nothing-Is-Lost/release/462630>.

Space Monkey. 2004. Psychotic Episode. Agitato Records (CD): AGE1035. <http://www.discogs.com/Space-Monkey-Psychotic-Episode/release/227416>.

Spaceships Of The Imagination. 2000. TIP.World (CD COMP): TIPWCD05. <http://www.discogs.com/Raja-Ram-Spaceships-Of-The-Imagination/release/36153>.

Star Sounds Orchestra. 1991. Planets. Fønix Musik Forlag (CD): FMF CD 1051. <http://www.discogs.com/Star-Sounds-Orchestra-Planets/release/420335>.

Star Sounds Orchestra. 1995. Inter Planetary Ambience (Live In London). i.t.p. recordings $(2 \times \mathrm{CD})$ : AEOS 001CD < http://www.discogs.com/ Star-Sounds-Orchestra-Inter-Planetary-Ambience-Live-In-London/release/625273 >.

Total Eclipse. 1994. Aliens / Sound Is Solid. Dragonfly Records (Vinyl, 12-inch): BFLT 16. <http://www.discogs.com/Total-Eclipse-Aliens-Sound-Is-Solid/release/12906>.

UR. 1991. The Final Frontier. Underground Resistance (Vinyl, 12-inch). UR-003. $<$ http://www.discogs.com/UR-The-Final-Frontier/release/2111 >.

X-102. 1992. Discovers The Rings Of Saturn. Tresor (2 x Vinyl, LP): Tresor 4. <http://www.discogs.com/X-102-Discovers-The-Rings-Of-Saturn/release/12764 >.

\section{FILMOGRAPHY}

Coney, John (dir). 1974. Space Is the Place. North American Star System. $<$ http://www.imdb.com/title/tt0072195/>.

Gruder, Ori (dir). 1998. Karahana: The First Psychedelic Trance Movie. <http://www.youtube.com/watch? $=$ mLg8E8SRw3w $>$.

Kubrick, Stanley (dir). 1968. 2001: A Space Odyssey. MGM, Stanley Kubrick Productions. <http://www.imdb.com/title/tt0062622/>.

Sextro, Maren and Holger Wick (dirs.). 2008. We Call it Techno! A Documentary About Germany's Early Techno Scene and Culture. Sense Music \& Media, Media Atelier, Germany. <http://www.imdb.com/title/tt1698597>. 